\title{
NATUR ALS MORALISCHE ANSTALT \\ DIE METEOROLOGIA PHILOSOPHICO-POLITICA \\ DES FRANZ REINZER, S.J., \\ EIN NATURWISSENSCHAFTLICHES EMBLEMBUCH \\ AUS DEM JAHRE 1698
}

\author{
CHRISTOPH MEINEL \\ Universität Hamburg, Institut für Geschichte der Naturwissenschaften
}

\section{RIASSUNTO}

La meteorologia tradizionale, impigliata nella cosmologia aristotelica più a lungo di altre parti della scienza naturale, è una scienza sparita e quasi dimenticata dalla ricerca storica. Colla sua sintesi straordinaria di trattato di meteorologia, libello d'emblema, e specchio di principe, la Meteorologia di Reinzer ci dà occasione di localizzare più precisamente la meteorologia premoderna nel suo contesto intellettuale ed istituzionale, e di mostrare le sue relazioni col pensiero scientifico, colle tradizioni della natura moralizzata o della teologia naturale, e col programma politico-didattico dei Gesuiti alla fine del Seicento.

\section{VORBEMERKUNG}

Ein zentrales Problem der wissenschaftsgeschichtlichen Methodik und Hermeneutik liegt bekanntlich in der Tatsache, daß der Interpret historischer Quellen nicht umhin kommt, Sach- und Gattungsbegriffe, Sichtweisen und Denkgewohnheiten seiner eigenen Erfahrungswirklichkeit bewußt oder unbewußt auf den historischen Gegenstand zu projizieren. Die Geschichte der Naturwissenschaften, deren Gegenstände gewissermaßen von Natur aus festzuliegen scheinen, ist dieser Versuchung immer wieder erlegen, gerade weil sie glaubte, von der historischen Invarianz 
der äußeren Realität ausgehen zu dürfen. Doch werden auf diese Weise Bereiche der geschichtlichen Wirklichkeit, die sich keinem der uns geläufigen Schemata fügen wollen, zwangsläufig perspektivisch verzeichnet, wenn sie nicht gänzlich außerhalb des von unserer Warte aus möglichen Blickwinkels bleiben. Die äußere, objektive Realität, die Realität der Dinge und Naturgesetze, ist eben nur insofern Gegenstand der Wissenschaftsgeschichte als einer historischen Disziplin, als diese äußere Realität ihren Niederschlag in einer inneren Erfahrungswirklichkeit der historischen Subjekte gefunden hat. Die historische Wirklichkeit, mit der es der Wissenschaftshistoriker zu tun hat, ist deshalb in erster Linie die erfahrene und bewertete, im Individuum abgebildete Welt, die Wirksamkeit für das Denken und Handeln gewinnt. Naturwissenschaftliche Systeme und Weltbilder sind nichts anderes als solche inneren Repräsentationen einer objektiven Realität der Natur. Walter Pagel, der bedeutende Erforscher des Paracelsismus, hat deshalb gefordert, anstelle der « nostrizentrischen» Interpretation, die von unserem Standpunkt aus urteilt, eine « idiozentrische » Betrachtungsweise zu wählen, die sich ihren Bezugspunkt im historischen Individuum und seiner Welt sucht. ${ }^{1}$ Erst dann kann sich, soweit dies überhaupt möglich ist, das vielleicht ganz anders strukturierte Bezugs- und Koordinatensystem der Wirklichkeitserfahrung und Wirklichkeitsbewältigung einer vergangenen Zeit erschließen. Oft dürfte sich dabei herausstellen, daß die jeweiligen Repräsentationen der äußeren Realität, die « historischen Erfahrungsräume », wie Fritz Krafft ${ }^{2}$ sie nennt, so sehr an Zeit und Ort gebunden sind, daß sie sich nicht ohne weiteres in die naturwissenschaftliche Wirklichkeitserfahrung der Gegenwart übersetzen lassen.

Die prinzipielle Inkommensurabilität von Kategorien der Wirklichkeit unterschiedlicher Epochen wird in der Wissenschaftsgeschichte besonders dort deutlich, wo wir es mit Wirklichkeitserfahrungen zu tun haben, wie sie uns heute nicht mehr begegnen. In der Wissenschaftsgeschichte ist dies der Fall bei den untergegangenen oder « verdrängten » Wissenschaften ${ }^{3}$ wie Magia naturalis oder Astrologie, Alchemie oder

1 W. PAGEL, Joan Baptist van Helmont: Reformer of Science and Medicine ( Cambridge Monographs on the History of Medicine »), Cambridge-London-New York 1982, S. IX.

2 F. KRAFFT, Das Selbstverständnis der Physik im Wandel der Zeiten: Vorlesungen zum historischen Erfabrungsraum physikalischen Erkennens, Weinheim 1982, S. 31-36; sowie ders., "Gegenstand und Methode der Wissenschaftsgeschichte der Naturwissenschaften », in Entwicklung und Selbstverständnis von Wissenschaften, hrsg. von H. J. BRAUN und R. H. KLUWE ("Studien zur Technik-, Wirtschafts- und Sozialgeschichte», Bd. 1), Frankfurt-Bern-New York 1985, S. 310-338.

3 Vgl. die Beiträge des Symposiums Verdrängte Wissenschaften, «Berichte zur Wissenschaftsgeschichte », 4, 1981, S. 1-110. 
Mnemotechnik. Aber auch die Meteorologie in ihrer alten Form ist ein Beispiel einer solchen, uns nicht mehr ohne weiteres zugänglichen Wissenschaft, auch wenn sie von Gegenständen der äußeren Natur handelt wie Wind und Regen, Blitz und Sternschnuppen, deren objektive Realität stets die gleiche geblieben ist.

\section{Einleitung}

Meteorologie, heute als Zweig der Geophysik eng auf die Physik der Atmosphäre begrenzt, war ehedem eine Wissenschaft, die den ganzen weiten Bereich des Stofflichen zwischen Himmel und Erde, ja auch Feuer, Dünste und Feuchtigkeiten unter der Erde umfaßte. Erst nach und nach hat diese weitgespannte Wissenschaft von den meteora einen um den anderen ihrer Gegenstände an benachbarte Disziplinen abtreten müssen: Regenbogen und Haloerscheinungen an die Optik, Kometen und Milchstraße an die Astronomie, Blitz und Donner an die Physik, Mineralien, Metalle und Mineralwässer an die Chemie, bis das Fach sich schließlich, auf die Kunde von Wind und Wetter reduziert, damit begnügen mußte, als die windigste unter den sich immer exakter gebärdenden Naturwissenschaften zu gelten. Von einer Meteorologie im modernen Sinne als Physik der Atmosphäre kann vor der zweiten Hälfte des 19. Jahrhunderts kaum die Rede sein.

Tatsächlich reicht die Tradition der alten aristotelischen Meteorologica weiter in die Neuzeit hinein, als man annehmen möchte. Noch Ludwig Friedrich Kämtz, der als einer der Begründer der akademischen Meteorologie in Deutschland gelten darf, behandelte im Schlußkapitel seiner 1840 erschienenen Vorlesungen über Meteorologie die "Problematischen Erscheinungen » der oberen Luftschichten wie Regenbogen, Polarlichter, Erdmagnetismus, Sternschnuppen und Feuerkugeln. ${ }^{4}$ Wie groß die Unsicherheit hinsichtlich der Zuordnung derartiger Erscheinungen selbst im 19. Jahrhundert noch war, zeigt sich allein daraus, daß Kämtz sich nicht scheute, die fabelhaften Berichte über angebliche Schwefel-, Blut-, Getreide- und Tier-Regenfälle trotz gewisser Vorbehalte als empirische Tatsachen anzuführen, und auch hinsichtlich der Herkunft der Eisenmeteorite war er sich ungeachtet der bereits 1794 von Ernst Florens Chladni dagegen vorgebrachten Einwände keineswegs sicher, ob es sich nicht doch um atmosphärische Bildungen handele, die ihre

4 L. F. KäмTZ, Vorlesungen über Meteorologie, Halle 1840, S. 561-586. 
Erklärung in metallischen Ausdünstungen der Erde finden könnten, wie dies schon die aristotelische Tradition angenommen hatte.

Die wissenschaftsgeschichtliche Behandlung der Meteorologie hat diesen Verhältnissen bisher kaum Rechnung getragen, ja, den vollkommen anders strukturierten Gegenstands- und Wissenschaftsbereich der frühen Meteorologie weitgehend verkannt. Indem sie sich die moderne, physikalisch-klimatologische Definition des Faches zu eigen gemacht hat, fielen all diejenigen Gebiete aus der historischen Betrachtung heraus, die für fast zwei Jahrtausende den Schwerpunkt der Wissenschaft von den meteora ausgemacht haben. Auch wenn man immer zugestehen wird, daß erst mit der Entwicklung von Thermometer, Barometer und Hygrometer im 17. Jahrhundert ein experimenteller Zugang zur Physik der Atmosphäre möglich wurde, so entspricht doch die Beachtung, die die Entwicklung der barometrischen und thermometrischen Meßverfahren seitens der Historiker erfahren hat, durchaus nicht der faktischen Bedeutung dieser experimentellen Verfahren für die meteorologische Wissenschaft des 17. Jahrhunderts. Symptomatisch in dieser Hinsicht ist die Darstellung bei Khrgian von 1959, der die Zeit bis zum 16. Jahrhundert auf knappen 20 Seiten abhandelt, um dann, nach einem Kapitel über die Entwicklung der ersten meteorologischen Instrumente, unter der Uberschrift «A New Science is Born » zur mathematischen Ableitung der barometrischen Höhenformel überzuleiten. ${ }^{5}$ Eine «idiozentrische » Geschichte der Meteorologie, die den Eigenarten der alten Wissenschaft von den meteora gerecht wird, ohne diese zur bloßen Vorgeschichte einer Physik der Atmosphäre zu reduzieren, wäre erst noch zu schreiben; sie dürfte dann aber auch an längst vergessenen Autoren wie Libert Froidmont und Jean-Baptiste Duhamel oder der Historia ventorum eines Francis Bacon, ja selbst an einem Außenseiter wie Franz Reinzer nicht vorübergehen.

\section{Franz Reinzers « Meteorologia philosophico-politica »}

Die Meteorologia philosophico-politica des Linzer Jesuitenprofessors Franz Reinzer aus dem Jahre 1698 ist ein Werk, das sich keiner literarischen oder wissenschaftlichen Gattung eindeutig zuordnen läßt. Da es der aufwendige Druck aber immerhin auf zwei lateinische und eine deutsche Ausgabe gebracht hat und in Bibliotheken auch heute noch keines-

5 A. Kh. Khrgian, Meteorology: A bistorical Survey [1959], Vol. I, 2nd ed., ed. by Kh. P. Pogosyan, Jerusalem 1970. 
wegs selten ist, dürfte die Meteorologia sich zur Zeit ihrer Entstehung einer gewissen Beliebtheit und keines schlechten Absatzes erfreut haben. Einzelne Exemplare tauchen gar nicht so selten auch heute noch im Handel auf. ${ }^{6}$ Doch sucht man den Namen ihres Autors in der wissenschafts- und meteorologiegeschichtlichen Literatur vergebens. ${ }^{7}$ Aber auch als Emblembuch blieb die Meteorologia trotz der Qualität ihrer Sinnbilder - von gelegentlicher bibliographischer Notiznahme in einschlägigen Ubersichten abgesehen ${ }^{8}$ - von der germanistischen und kunstgeschichtlichen Emblemforschung unbeachtet oder findet sich bloß beiläufig als ein Kuriosum erwähnt, das die Neigung dieses Genres zu « the elaborate and the strange ${ }^{9}$ belegen soll. In der Tat entzieht sich das Werk einer Vereinnahmung durch den von Andrea Alciatos Emblematum liber (1531) geprägten Gattungsbegriff des Emblembuchs ebenso wie der Zuordnung zur Jesuitenemblematik des 17. Jahrhunderts oder der Subsumierung unter eine der von der neueren Forschung entwickelten Emblemtheorien. Als akademische Disputationsschrift fällt Reinzers Werk allein schon durch seinen Umfang und den künstlerisch-drucktechnischen Aufwand aus dem Rahmen des Üblichen heraus; als Fürstenspiegel schießlich ist ihr gelehrt-naturwissenschaftlicher Gehalt überraschend und ohne Parallele in vergleichbaren Werken dieses Genres.

In der Tat bedarf das Zusammentreffen so heterogener Traditionen und Stilelemente der Erklärung. Diese wird zunächst bei der Entstehungsgeschichte anzusetzen haben, dann die Stellung des Werkes in der meteorologischen und der emblematischen Tradition beleuchten, um schließlich den historischen Ort dieser emblematisch verbrämten scientia meteororum zu bestimmen. Wissenschaftsgeschichtlich wird dann deutlich werden, daß bestimmte Bereiche der frühneuzeitlichen Naturwissenschaft einem historischen Erfahrungs- und Geltungsraum angehören, der die Bezüge zwischen Natur, Naturwissenschaft und Lebenswirklichkeit

6 Das Jabrbuch der Auktionspreise nenn' zwischen 1970 und 1984 die Ausgabe « 1697 » zweimal, die von 1698 viermal, die von 1709 neunmal und die von 1712 viermal. Siehe auch D. A. Wittop Koning, J. B. van Gelder, «Die Offizin aus der Meteorologia philosophica-politica [sic] des Fr. Reinzer ", "Beiträge zur Geschichte der Pharmazie », 36, 1984, Nr. 24, S. 210.

7 Eine Ausnahme macht lediglich G. Hellmann, Entwicklungsgeschichte des meteorologischen Lebrbuchs, in ders., "Beiträge zur Geschichte der Meteorologie», Bd. II («Veröffentlichungen des Königl.-Preußischen Meteorologischen Instituts», 296), Berlin 1917 , S. 1-33, hier S. 85.

8 M. PRAz, Studies in Seventeenth-Century Imagery, 2nd ed. («Sussidi Eruditi », 16), Roma 1964, S. 468; J. LANDWEHR, German Emblem Books, 1531-1888: A Bibliography («Bibliotheca Emblematica», 5), Utrecht-Leiden 1972, S. 121, Nr. 492-495; G. R. DimLer, S.J., A Bibliographical Survey of Jesuit Emblem Authors in German-Speaking Territories: Topography and Themes, "Archivum Historicum Societatis Jesu ", 45, 1976, S. 129-138.

9 Praz, Studies (wie Anm. 8), S. 193. 
in einer für uns nur noch schwer nachzuvollziehenden Weise prägte. Denn Wissenschaft erfährt ihre konkrete historische Ausprägung ja nicht allein von den Realdingen, mit denen sie umgeht, sondern auch von der Bedeutung, die die Gesellschaft oder Einzelne diesen Realdingen und der Beschäftigung mit ihnen jeweils zugemessen haben. Gerade in dieser Hinsicht verdient auch ein so ungewöhnliches Buch wie Reinzers $M e$ teorologia philosophico-politica wissenschaftshistorisches Interesse.

Wenden wir uns zunächst der Entstehungsgeschichte des Werkes zu, soweit diese sich rekonstruieren läßt. Im August $1698^{10}$ hatte Johann Bernhard Coelestin Graf von Rödern an dem von den Jesuiten geleiteten Akademischen Gymnasium der oberösterreichischen Stadt Linz 50 Conclusiones ex universa philosopbia ${ }^{11}$ zu verteidigen, deren Gegenstände von der Logik über die Naturlehre und die Metaphysik bis hin zum Beweis der existentia Dei reichten. Der Schwerpunkt lag bei physikalischen Themen (Conclusiones 11-40): Ihre Auswahl läßt die enge Zugehörigkeit zur neuaristotelischen Naturphilosophie nur zu deutlich erkennen. Da wird die privatio als eigenständiges Prinzip neben Form und Materie behauptet, da wird eine materia prima als Substrat aller stofflichen Prozesse vorausgesetzt, da ist das Kontinuum potentiell unbegrenzt teilbar, da kann die Welt nicht von Ewigkeit her bestanden haben, und bewegt sich der Himmel $a b$ extrinseco. Es bedürfte kaum noch der Hinweise auf die Nichtexistenz partieller formae und die Unmöglichkeit mehrerer animae in ein und demselben Lebewesen, um den Verfasser eindeutig der thomistischen Tradition zuzuweisen, die an den Hochschulen des katholischen Europa bis ins frühe 18. Jahrhundert hinein auch den naturwissenschaftlichen Unterricht bestimmte. Als Zeichen der Anerkennung für diese Probe akademischer Gelehrsamkeit sollte Franz Joseph Graf von Lamberg, wirklicher Geheimer Rat und Oberhauptmann der Landschaft Oberösterreich, dem Respondenten im Namen des Königs Josephs I. eine goldene Kette verehren. Aus Anlaß dieser Begebenheit entstand die wohl eigenwilligste und aufwendigste Disputationsschrift, die je aus einer deutschen hohen Schule hervorgegangen ist.

\subsection{Die Drucke}

Die Druckgeschichte der Meteorologia philosophico-politica wird dadurch ein wenig unübersichtlich, daß von der ersten Auflage unter-

10 Bei dem häufig vorkommenden Datum 1697 dürfte es sich um einen Druckfehler handeln; vgl. auch den folgenden Abschnitt 3.1.

11 Meteorologia (1698), fol. Qqv. 
schiedliche Druckzustände existieren, die bibliographisch für eine gewisse Verwirrung gesorgt haben. Erst der Vergleich vieler Exemplare klärt die Verhältnisse. In der ersten Fassung lautet der weitschweifige Titel:

METEOROLOGIa | PHILOSOPHico- | POlitica, | In duodecim Dissertationes per Quæstiones Meteo|rologicas \& Conclusiones Politicas divisa, appositisque | Symbolis illustrata: | HONORI AUGUSTI ROMANORUM REGIS | JOSEPHI I. | Inscripta | Ab Illustrissimo Domino | JoAnNe bernardo Cellestino, | Sac. Rom. Imp. Comite à Rödern, Austriaco | Manseensi; | Dum sub gloriosis Ejusdem auspiciis Uniuersam Philosophiam publicè | propugnandam in Cæsareo-Academico Societatis JESU Gymnasio Lincensi susciperet, | \& ab eadem Augusta Majestate per Legatum | Excellentissimum \& Illustrißimum Dominum | DN. FRANCisCum Josephum, | S. R. I. Comitem à Lamberg, S. C. M. Actualem Intimum Consiliarium | \& Superioris Austriæ supremum Capitaneum, nec non Aurei Velleris | Equitem, \&c. \&c. aureo torque donaretur, | PRESIDE | R. P. FRANCISCo ReInzer, è Societate JESU, | AA. LL. \& Philosophiæ Doctore, ejusdémque Professore | Ordinario. | Mense Augusto, Die Anno mDCXCvir. | Cum Privilegio Sacræ Cæs. Maj. | Auguste vindelicorum, | Impensis JeREMIe wOLFII, Chalcographicæ Artis Propolæ.

$2^{\circ}$ (ca. $31 \times 20 \mathrm{~cm}$ ); Titelkupfer, [IV], 424, [IV] S., 83 Kupferstiche im Text.

Ein früher Druckzustand dieser Ausgabe ist in einem Exemplar der Bayerischen Staatsbibliothek ${ }^{12}$ faßbar, das nicht nur sämtliche Schriftbänder des Titelkupfers - das dem Titelblatt stets bloß vorangeklebt, nicht eingebunden ist - vermissen läßt, sondern in dem auch die Textkupferstiche 31,70 und 76 verdruckt und nachträglich durch die richtigen Picturae überklebt sind. Später kommt dies nur noch bei Pictura 31 vor, die in vielen Exemplaren die irrtümlich an diese Stelle gedruckte Pictura 39 überdeckt. ${ }^{13}$

Weiter erfahren wir aus dem Titel, daß der Druck von dem bedeutenden Augsburger Kupferstecher und Kupferstichverleger Jeremias Wolff ${ }^{14}$ finanziert wurde. Dieser hatte Beziehungen zum Augsburger Jesuitenkolleg, und auf diesem Wege ist vielleicht der Kontakt zur Linzer

12 BStB München, Signatur Res. $2^{\circ}$ L. eleg. m. $94^{*}$.

13 So in den Exemplaren der Bibliothek des Deutschen Museums, der Österreichischen Nationalbibliothek, der Staats- und Universitätsbibliothek Hamburg. Das letztere hat überdies "Intimm » anstelle von "Intimum » im Titel. Weitere Exemplare der Ausgabe Augsburg: Wolf 1698 in der Staats- und Stadtbibliothek Augsburg, der Bibliothek der University of Minnesota, Minneapolis, und der Folger Shakespeare Library.

14 Jeremias Wolf(f), 1663-1724, unterhielt einen bedeutenden Kupferstichverlag, für den die besten Stecher seiner Zeit arbeiteten; vgl. Allgemeines Lexikon der bildenden Künstler, begr. von U. THIEME und F. BECKER, Bd. 36, Leipzig 1947, S. 206. 
Jesuitenschule hergestellt worden. ${ }^{15}$ Für die Wahl des auswärtigen Druckortes dürfte nicht zuletzt ausschlaggebend gewesen sein, daß es in Linz keinen Buchdrucker gab, der den technischen Anforderungen dieses Satzes gewachsen gewesen wäre. ${ }^{16}$ Mit Augsburg dagegen konnte sich so leicht kein anderer Druckort messen: Nicht nur war hier schon 1531 mit Alciatos Emblematum liber der Prototyp aller Emblembücher erschienen, sondern auch 1595 Jakob Spanmüllers Floridor, das früheste Jesuiten-Emblembuch gedruckt worden, und gegen Ende des 17. Jahrhunderts stieg die Stadt zum Buchhandelszentrum für den gesamten katholischen Süden Deutschlands auf.

Zugleich mit der von Jeremias Wolf in Augsburg verlegten, für den Buchhandel bestimmten Ausgabe dürfte eine vermutlich den Autoren selbst zugedachte Teilauflage hergestellt worden sein, die sich allein dadurch unterscheidet, daß ihr das kaiserliche Privileg auf dem Titelblatt fehlt und anstelle des Verlegers der Drucker mit «Typis Antonii Nepperschmidii " ${ }^{17}$ firmiert. Von dieser Ausgabe mit dem Erscheinungsjahr 1698 ist mir nur das Exemplar der Osterreichischen Nationalbibliothek ${ }^{18}$ bekannt, das auch eine eigene Variante des Titelkupfers bietet: Gegenüber dem endgültigen Zustand (Abb. 1) tragen die Schriftbänder kleinere, schwerer lesbare Aufschriften.

Die meisten unter dem Signet des Augsburger Druckers Anton Nepperschmid umlaufenden Exemplare ${ }^{19}$ weisen indes die Jahreszahl 1697 auf, weil die mittlere, schon in den Exemplaren mit « MDCXCvIII 》 beschädigte Type «I » während des Druckes der restlichen Auflage herausgefallen war. In einigen Fällen ist die fehlende « $I$ » von alter Hand ergänzt. ${ }^{20}$ In sämtlichen Fassungen bleibt der Tag der Disputation offen, so daß anzunehmen ist, daß der Druck wie üblich bereits vor diesem Termin abgeschlossen war.

15 Freundlicher Hinweis von Frau Dr. Salzbrunn, Staats- und Stadtbibliothek Augsburg.

16 Bekanntlich hatte schon Kepler in Linz mit der Drucklegung seiner Werke Schwierigkeiten gehabt.

17 Seit 1687 als Buchdrucker in Augsburg, von 1709 bis vor 1712 in Memmingen. Aus seiner Offizin kennen wir noch JohanN BartholemäUs Franks Praxis geometrica universalis oder allgemeine Lebre vom Feld-Messen, Augsburg 1705. Vgl. auch C. VISEL, Buchdruckers Dank, «Börsenblatt für den Deutschen Buchhandel »(Frankfurt), 12, 1956, S. $170-172$.

18 ÖNB Wien, Signatur 74.B.38. Vgl. LANDWEHR (wie Anm. 8), S. 493.

19 Exemplare in der BStB München, der UB Wien, der Bibliothèque Nationale, der Studienbibliothek Linz; vgl. auch Praz (wie Anm. 8), S. 468; LANDWEHr (wie Anm. 8), S. 492. Seattle.

20 Deutsches Museum Bibliothek (Signatur 1936 B 177); University of Washington, 
1709, ein Jahr nach dem Tode Reinzers, ließ der Verleger Jeremias Wolf « auf vielfachen Wunsch » einen berichtigten Neudruck des Werkes folgen, den der Augsburger Drucker Peter Detleffsen in größtmöglicher Anlehnung an die Typographie der Erstausgabe und unter Verwendung der ursprünglichen Kupferplatten besorgte:

METEORO|LOGIA | PHILOSOPHICO- | POLITICA, IN DUODECIM DISSERTATIONES | PER QU.ESTIONES METEOROLOGICAS | ET CONCLUSIONES POLITICAS DIVISA, APPO|SITISQUE SYMBOLIS ILLUSTRATA: | OLIM | HONORI | AVGVSTI ROMANORUM REGIS | JOSEPHI I. | INSCRIPTA | NUNC DENUO AD MULTORUM DESIRE|RIUM IN LUCEM CORRECTIOR EDITA, | AUTHORE | REVERENDO PATRE | FRANCISCO REINZER, | è SOCIETATE JESU, AA. LL. ET PHILOSOPHIE, | NEC NON ss. Theol. DOCTORE. | Cum Privilegio Sacræ Cæs. Maj. | augusta VINDElicorum, | Impensis JeREMIÆ wOlfiI, Chalcographicæ Artis Propolæ. | Typis PETRI DETLEFFSII. | Anno DCCIX [sic!]

$2^{\circ}$ (ca. $31 \times 20 \mathrm{~cm}$ ); Titelkupfer, [VI], 424, [V] S., 83 Kupferstiche im Text.

Hier nun ist Franz Reinzer, der inzwischen zusätzlich zu seinem Lizentiat der Freien Künste und der Philosophie noch einen theologischen Doktortitel aufzuweisen hat, als einziger Textautor genannt, auch fehlt der Bezug auf den ursprünglichen Entstehungsanlaß, die Disputation des Grafen von Rödern; ${ }^{21}$ es fehlen Widmungsseite und Dedikation an Joseph I. sowie die Liste der disputierten Conclusiones am Schluß. Diese Auflage ist relativ häufig anzutreffen; ${ }^{22}$ allein der National Union Catalog weist 10 Standorte nach.

Drei Jahre später schließlich brachten der gleiche Drucker und Verleger eine deutsche Übersetzung heraus, die mit geringfügigen Abweichungen inhaltlich der Ausgabe von 1709 folgt.

METEORologia | PHilosophico- | POLitica, | Das ist: | Philosophische | und | Politische | Beschreib= und E:klärung der Meteorischen, | oder in der obern Lufft erzeugten Dinge; | In Zwölff zerschiednen | Aus Meteorologischen Fragen/ und Politischen Schluß $=\mid$ Reden bestehenden; wie auch mit zugleich untermischten schönen $\mid \operatorname{Sinn}=$ Bildern gezierten $\mid$ Abtheilungen | Sonderbahren Fleisses ehedem verfasst | Durch | Den Ehrw. P. FRANCISCUM ReInzer, S.J. AA. LL. | \& Phil. D. \& Prof. Ord. in Gymn. Lincensi \&c.

21 Lediglich die Parenthese " ut non nostro, sed Illustrissimi Domini Comitis defendentis desiderio facimus satis $"$ in der an den Leser gerichteten Vorrede ist versehentlich stehengeblieben und erst in der deutschen Übersetzung fortgelassen.

22 Exemplare in der BStB München, der Bibliothek des Deutschen Museums, der Staats- und Stadtbibliothek Augsburg, der Biblioteca Mediceo-Laurenziana Florenz. 
Anjetzo aber | Wegen der darinnen enthaltnen raren und anmuthigen Mate| rien/ curiosen Gemüthern zu Gefallen/ und zu nutzlicher Ergötzung/ nebst erst/gedachten Authoris Vor = Ansprach an den Leser/ aus dem Latei/nischen in das Teutsche übersetzt. | Augspurg/ I In Verlegung Jeremiæ Wolffen/ Kunsthändlern. | Gedruckt bey Peter Detleffsen/ 1712.

$2^{\circ}$ (ca. $\left.32 \times 22 \mathrm{~cm}\right)$; Frontispiz, [VI], 424, [IV] S., 83 Kupferstiche im Text.

Obgleich in der Landessprache an ein breiteres Publikum gerichtet, scheint die deutsche Übersetzung weniger weit verbreitet als die lateinischen Versionen..$^{23}$ Die Gesamtzahl der gedruckten Exemplare sämtlicher Auflagen dürfte - mit der üblichen Unsicherheit derartiger Angaben unter 1000 geblieben sein; denn Frontispiz und emblematische Kupferstiche sind in allen Ausgaben von denselben Platten gedruckt, wobei auch die letzte deutsche Auflage nur geringfügige, auf Abnutzungen der Druckplatte zurückzuführende Qualitätseinbußen erkennen läßt.

\subsection{Aufbau des Werkes}

Von der Komposition her stellt sich die Meteorologia als Mischform aus gelehrt-naturwissenschaftlichem Kompendium der Meteorologie, didaktischem Emblembuch, moralisierendem Fürstenspiegel und akademischer Disputationsschrift dar, die der adelige Respondent seinem Landesherren gewidmet hatte. Der fürstliche Adressat Joseph I. war 1690 zum römisch-deutschen König gewählt worden und sollte 1705 seinem Vater Leopold I. auf den Kaiserthron nachfolgen, wo er im Spanischen Erbfolgekrieg sein politisches Geschick unter Beweis stellen konnte, wenn auch sein früher Tod - Joseph starb 1711 an den Pocken - die militärischen Erfolge Österreichs dann zunichte machte. Dem Feldherren, dem Staatsmann und dem Gelehrten Joseph gilt die devote, überschwengliche Widmungsvorrede aus der Feder des Grafen Roedern. Ihr einleitender Satz verrät die Motive des Autors deutlich genug: Ut finis coronet opus, in Te coronato vertice metam figit Philosophia mea. ${ }^{24}$ Einem Herrscher, der wie Joseph den Gelehrten und den Monarchen in

23 Exemplare in der British Library, der Bibliothèque Nationale, der Staats- und Stadtbibliothek Augsburg, der Studienbibliothek Linz, der UB Wien und der Bibliotheca Mediceo-Laurenziana Florenz. Der National Union Catalog nennt 7 Standorte in den USA; vgl. auch LANDWEHR (wie Anm. 8), S. 495.

24 Meteorologia (1698), fol. a2r. 
einer Person vereine, empfiehlt Roedern das Werk als eine kongeniale Schöpfung:

Meteorologiam ergo Philosophico-Politicam, sive rerum sublimium rationem Politicis exornatam placitis Augustis manibus defert, ut sublimis ille animi et mentis vigor, qui Te pari gradu et Regem et Philosophum constituit, affinem sibi inveniret materiam. ${ }^{25}$

Eine Beschreibung des mythologisch-allegorischen Titelkupfers (Abb. 1), das die Früchte von Frieden und Krieg vorstellen soll, schließt sich an. Joseph wird hier als Herr über Krieg und Frieden, als Herrscher aber auch über die irdischen Elemente verherrlicht, der seine Herrschaftsmittel Strenge und Güte, timor und amor, zum Ruhme Österreichs weise gebraucht: Vor dem Hintergrund zweier befestigter Städte, von denen die eine in der Sonne ihres Reichtums erstrahlt, die andere in Schutt und Asche sinkt, tobt eine Reiterschlacht. Vordergrund und Luftraum sind von mythologischen und allegorischen Gestalten bevölkert. Mit Personifikationen der vier Elemente, Blitz und Regen, Wind und Kometen, Bergbau- und Meeresszenerie sind die Naturgewalten ins politische Geschehen einbezogen. In der Mitte trägt ein Engel die Fanfaren Timore und Amore, versinnbildlicht in der zerstörerischen Gewalt des Blitzschlages und der vereinigenden Kraft des Magneten, darüber, auf den Schwingen eines blitzeschleudernden Adlers, die in zwei Hälften geteilte Erdkugel, von Osterreichs Krone zusammengehalten, und hoch über allem das Bildnis des jugendlichen Königs.

Auf die Widmung folgt eine Vorrede Ad benevolum lectorem ${ }^{26}$ aus der Feder Franz Reinzers, in der dieser über das Zustandekommen des aufwendigen Disputationsdruckes berichtet:

Diese Bücher nun haben wir [nicht auf unseren Wunsch hin, sondern um dem Verlangen des illustren Respondenten, des Herrn Grafen, Genüge zu tun ${ }^{27}$ ingedenck des Spruchs: Omne tulit punctum, qui miscuit utile dulci,

Wer Lust und Nutzbarkeit recht hat gemengt,

Der hat den Zweck erlangt/ wornach er ringt:

in gegenwärtigem Wercklein nach Anleitung nicht eines oder des andern (wie der geneigte Leser ersehen wird) sondern vieler Scribenten in Zwölff Abtheilungen zu erklären/ und mit Historischen sowohl/ als Erfahrungs=Blumen

25 Meteorologia (1698), fol. a2r-v.

26 Meteorologia (1698), fol. a3v. Vorrede.

27 Diese hier übersetzte Passage findet sich nur in den lateinischen Ausgaben der 
(so doch von wenigen/ die bißhero von den Meteoren geschrieben/ beschehen) auszuschmücken uns fürgenommen. ${ }^{28}$

Zu diesem Zwecke habe er, so fährt Reinzer fort, die wissenschaftlichmeteorologischen Abhandlungen mit passenden Sinnbildern verbunden, « auf daß auch das Aug (da inzwischen das Gemüth mit Philosophischer Wollust sich ergötzet) seine Vergnügung haben; und der Verstand die beschriebene Phænomena gleichsam im Bild beschauen könte ". ${ }^{29}$

Entsprechend diesem Plan werden in 12 Dissertationes oder « Abtheilungen » die einzelnen Gegenstände der Meteorologie nach der üblichen Aristotelischen Einteilung in Feuermeteore, Luftmeteore und Hydrometeore unter Einschluß der Wässer, Mineralien und Metalle des Erdreichs recht ausführlich abgehandelt. Eine jede Dissertatio ist in Quaestiones unterteilt, auf die als Conclusio politica oder "Politische Schluß= Rede » jeweils die emblematische Entwicklung eines moralischpolitischen Analogons zum dargelegten naturwissenschaftlichen Sachverhalt im typischen dreiteiligen Emblemschema folgt: Unter einer sentenzenhaften Überschrift die Pictura mit kreisförmigem Bildfeld (11$12 \mathrm{~cm}$ Durchmesser) auf quadratischem Rahmen (ca. $13 \times 13 \mathrm{~cm}$ ), deren runder Innenrahmen die Inscriptio oder das Motto trägt. Es folgt die Subscriptio, die Auslegung des Dargestellten, unter reichlicher Heranziehung antiker und biblischer Belegstellen und eingestreuter poetischer Texte. In der deutschen Version schließt dieser Teil mit einer Wiederholung der Inscriptio samt zweizeiliger deutscher Reimübertragung, gefolgt von der poetischen Zusammenfassung des politisch-moralischen Gehalts in einem. vierzeiligen lateinischen Distichon samt sechszeiliger Übertragung ins Deutsche.

Insgesamt überrascht die Meteorologia philosophico-politica durch die Heterogenität ihrer Komponenten, wobei selbst sprachlich-stilistisch die naturwissenschaftlichen und die poetisch-moralischen Texte so auffällig differieren, daß man an verschiedene Verfasser denken möchte. ${ }^{30}$ Erneut stellt sich damit die Frage, inwieweit das schulische Umfeld ihrer Entstehung und die Biographie der Autoren das Zusammentreffen so unterschiedlicher Elemente verständlich machen können.

28 Meteorologia (1712), fol. )(2.

29 Meteorologia (1712), fol. )(2r-v.

$30 \mathrm{Da}$ in der Tat der Respondent J. B. von Roedern die Conclusiones Politicae verfaßt hat, ist nicht völlig ausgeschlossen, zumal gelegentlich vom Praeceptor in der dritten Person die Rede ist (z.B. Meteorologia; 1698, S. 282); doch mag es sich dabei, wie bei Disputationsschriften so oft, auch um ein bloßes Stilmittel handeln. 


\subsection{Die Autoren.}

Franz Reinzers Lebensweg läßt sich nur in einzelnen Stationen fassen. ${ }^{31}$ Am 12. Oktober 1661 in Graz geboren, trat er im Oktober 1678 in den Jesuitenorden ein und hat hier gewiß das übliche Ordensstudium absolviert. Nach der Gepflogenheit der Jesuiten, ihre Lehrer jeweils nur für kurze Zeit an ein und demselben Ort zu belassen, unterrichtete Reinzer dann nacheinander an verschiedenen Schulen und Kollegien; zunächst, als Magister, Grammatik und Humaniora, dann auch Rhetorik im Wiener Profeßhaus, danach für ein Jahr am Gymnasium zu Passau, erscheint er 1686/87 als Magister poeseos, d.h. als Lehrer der zweitobersten Klasse, am Jesuitengymnasium der Stadt Linz. Anschließend ging er als Lehrer der Rhetorik wieder nach Passau zurück. Nach seiner Priesterweihe und Promotion zum Doktor der Philosophie 1692 in Wien wurde er noch im gleichen Jahr als Rhetorikprofessor an die Wiener Philosophische Fakultät verpflichtet. Aber auch dort hielt es ihn nur für kurze Zeit: 1694 kehrte er als Professor für Ethik und Präfekt der Niederen Studien an das Linzer Jesuitengymnasium zurück. ${ }^{33} 1695 / 96$ unterrichtete er Logica, d.h. die unterste Klasse des philosophischen Studienkurses, 1696/97 Physica und 1697/98 schließlich Metaphysik. ${ }^{34}$

Es ist gewiß kein Zufall, daß die Entstehung der Meteorologia philosopbico-politica genau in jenes Jahr fällt, in dem Reinzer, der in Linz als Lehrer der Poesie begonnen hatte, das Lehrfach der Physik innehatte, wozu auch die Kommentierung der Aristotelischen Schriften De generatione et corruptione und Meteorologica gehörte. Sein literarisches Hauptwerk ist damit zugleich ein Spiegel seiner Lehrtätigkeit am Linzer Akademischen Gymnasium.

31 Zur Biographie vgl. C. Sommervogel (Hrsg.), Bibliothèque de la Compagnie de Jésus, Pt. I, Tome VI, Bruxelles-Paris 1895, Sp. 1640-1641; J. N. Stoeger, Scriptores Provinciae Austriacae Societatis Jesu ab eius origine ad nostra usque tempora, WienRegensburg 1856, S. 297-298; J. ScHMIDT, Linzer Kunstcbronik, Tl. 2, Linz 1951, S. 119; sowie bes. CH. Ensle, Die Jesuitenprofessoren an der Wiener Philosophischen Fakultät (1623-1711), Phil. Diss. Universität Wien, Wien 1970, S. 171-172. Herrn Univ.-Prof. Dr. Harry Kühnel, Krems an der Donau, danke ich für Nachforschungen bezüglich Reinzers Stellung in Krems.

$32 \mathrm{Vgl}$. H. Schardinger, Die Rektoren (Superioren), Praefekten und Lebrer am Linzer Gymnasium unter den Jesuiten (1608-1773), «Historisches Jahrbuch der Stadt Linz 1955 », 1955, S. 135-196.

33 Hauptquelle ist der Catalogus studiosorum in Lincensi Gymnasio, 1646-1773, Oberösterreichisches Landesarchiv Linz, Hs 12a; Schardinger (wie Anm. 32).

$34 \mathrm{Vgl}$. J. LenzenWeger, Das Jesuitenkollegium zu Linz als Ausgangspunkt einer o.ö. Hochscbule, «Jahrbuch der Stadt Linz 1951 », 1951, S. 41-81, hier S. 69-70. 
Später begegnet uns Reinzer als Professor am Kollegium in Passau, wo er zwei Jahre lang Moraltheologie lehrte, Präses einer marianischen Kongregation und Präfekt des Gymnasiums war. Als Professor der Moraltheologie ging er danach für ein Jahr an die Grazer Universität und vier weitere Jahre nach Passau, wo er abermals als Präfekt des Gymnasiums fungierte. 1705 erfolgte dann in Wien die Promotion zum Doktor der Theologie und zugleich die Ernennung zum Professor für Kontroverstheologie. ${ }^{35}$ Im November 1707 wurde Reinzer schließlich zum Rektor des Kollegiums zu Krems an der Donau bestimmt, wo er am 28. (anderen Quellen zufolge am 25.) April 1708 gestorben ist.

Als Schriftsteller ist Franz Reinzer, sieht man von der Meteorologia philosopbico-politica ab, kaum hervorgetreten. Sein Erstlingswerk scheint ein emblematisch geziertes Schriftchen im Duodezformat mit dem Titel Problemata politica quinquaginta oratione deducta et symbolis ornata (Wien 1690) gewesen zu sein. ${ }^{36}$ Drei Jahre danach gab er in Wien als akademische Gelegenheitsschrift anläßlich einer Promotion eine Sammlung von Lobreden auf Kaiser Leopold I. heraus. ${ }^{37}$ Später, in Passau, folgten eine Blütenlese aus den Briefen des jüngeren Seneca mit dem Titel Seneca cbristianus ${ }^{38}$ sowie zwei Andachtbüchlein.

Wenn wir dem bereits zitierten Bericht Reinzers über das Zustandekommen der Meteorologia pbilosophico-politica Glauben schenken wollen, so war das Ganze offenbar die Idee seines Schülers Johann Bernhard Coelestin Graf von Roedern, der im Akademischen Gymnasium zu Linz 50 physikalische und allgemeinphilosophische Thesen öffentlich verteidigen und dieses Ereignis, vielleicht das einzige Glanzlicht seiner akademischen Karriere, angemessen dokumentiert wissen wollte. Johann Bernhard, dessen genaue Lebensdaten unbekannt sind, war ein Sohn des Johann Ignatius Roedern und der Maria Elisabeth von Zierotin aus einer landsässigem oberösterreichischen Familie, die aus Berg bei Rohrbach im Mühlviertel kam. ${ }^{39}$ In den Matrikeln des Gymnasiums erscheint sein Name 1693, 1694 und 1695 - dem Jahr, in welchem Reinzer Präfekt der

35 Freundliche Hinweise auf Reinzers akademischen Werdegang und die noch nicht publizierte Wiener Matrikel verdanke ich Herrn Universitäts-Archivar Dr. Kurt Mühlberger vom Archiv der Universität Wien.

36 Angaben bei Sommervogel (wie Anm. 31); Exemplare dieses und der folgenden Titel waren nicht zu ermitteln.

37 Quinque Panegyrici de Caesareis virtutibus Leopoldi M. Rom. Imp., Wien 1693.

38 Seneca christianus, i.e. Flores cbristiani ex L. Aenae Senecae Epistolis collecti, Passau 1700.

39 Freundlicher Hinweis des Oberösterreichischen Landesarchivs Linz. Die genealogische Zuweisung ist jedoch nicht völlig befriedigend und differiert von den Angaben in: Die Wappen des Adels in Oberösterreich (J. SIEBMACHER's großes Wappenbuch, Bd. $27=$ Reprint von Bd. IV/5 der Ausgabe Nürnberg 1904), Neustadt a.d. Aisch 1984, S. 296-297. 
Lateinschule war - mit der Herkunftsangabe Mondsee, die sich auch auf dem Titel der Meteorologia findet. Über den weiteren Lebensweg Roederns ist nur soviel bekannt, $\mathrm{da} ß$ er als kaiserlicher Rittmeister des Houttoischen Kürassierregiments starb. ${ }^{40}$

Der Zweck, den Roedern mit seiner aufwendig gestalteten Disputationsschrift verfolgte, dürfte am Wiener Hofe zu suchen sein. Seine Widmungsvorrede an Joseph I. ist in dieser Hinsicht ja deutlich genug; aber auch für Franz Reinzer, den Jesuitenprofessor, wird die Gelegenheit, auf diesem Wege allerhöchsten Orts Gefallen zu finden, nicht unwillkommen gewesen sein. Vielleicht hatte die Beziehung zum Wiener Hof eben jener Franz Joseph Lamberg, Landgraf zu Leuchtenberg, ${ }^{41}$ vermittelt, der dem Respondenten bei der feierlichen Disputation im Namen des Kaisers die goldene Kette zu überreichen hatte.

Die Frage der Autor- bzw. Urheberschaft der Meteorologia philosopbico-politica ist also, auch wenn man sie bloß auf den Text bezieht, wie bei dem meisten Emblembüchern schwierig zu beantworten und nicht von der Entstehungsgeschichte des Bandes zu trennen. $\mathrm{Ob}$ man Roedern die Idee, Reinzer die Abfassung zuweisen darf? Daß die enge Verquickung von Bild und Text von Anfang an auch die Mitwirkung des Bildautors erforderte, ist anzunehmen. Es lag daher nahe, daß man sich für den Bildschmuck an einen ortsansässigen Zeichner wandte: Auch wenn nicht alle Kupferstiche der Meteorologia philosopbico-politica bezeichnet und viele nach fremden Vorlagen gearbeitet sind, dürften sämtliche Zeichnungen von Wolfgang Joseph Kadoriza (oder Kadorizi) stammen. Dieser hatte 1697 in Linz geheiratet, dort als Maler das Bürgerrecht erworben und ist noch bis um 1730 in der Donaustadt nachzuweisen. ${ }^{42}$ Ein Selbstbildnis von 1707 aus Wiener Privatbesitz zeigt den Maler zwergwüchsig und mit grotesk großer Brille im häuslichen, ärmlich verwahrlosten Atelier, dessen Wände mit allerlei Fratzen, Stilleben und Landschaften behangen sind, ihm zur Seite zwei Kleinkinder sowie seine Frau, die über dem Anrühren der Farben eingeschlafen ist. ${ }^{43}$

40 So auch bei Zedler, der den Vornamen des Vaters allerdings mit Ferdinand Ignatius angibt; vgl. Großes und vollständiges Universal-Lexikon aller Wissenschaften und Künste, Bd. 32, Halle: J. H. Zedler, 1742, Sp. 265.

41 Franz Joseph Lamberg (1637-1712) war ein enger Vertrauter des Kaisers Leopold I., mit diesem gemeinsam erzogen, 1662 kaiserlicher Kammerherr, dann Wirklicher ReichsHofrat, 1685 Geheimer Rat und 1686 Landeshauptmann in Oberösterreich. Verschiedentlich in diplomatischer Mission unterwegs, hatte er 1694 den Ritterorden des Goldenen Vlieses empfangen und wurde schließlich 1711 in den Reichsfürstenstand erhoben. Vgl. Zedler (wie Anm. 40), 16 (1737), Sp. 290-291.

42 Vgl. J. Schmidt, Linzer Kunstchronik, T1. 1, Linz 1951, S. 111; THIEME-BeCKeR (wie Anm. 14), 19, 1926, S. 412.

43 TH. VON FRIMMEL, Der Linzer Miniaturmaler Wolfgang Josef Kadorizi, «Blätter für Gemäldekunde », 1, 1905, S. 93-94. 


\subsection{Das schulische Umfeld}

Auch das lokale und akademisch-schulische Milieu, aus dem die $\mathrm{Me}$ teorologia philosophico-politica stammt, verdient Beachtung. Linz, das seine wirtschaftliche Bedeutung vor allem seiner günstigen Verkehrslage verdankt, blieb lange Zeit politisch von Niederösterreich, kirchlich vom Bistum Passau abhängig. Als Hochburg des österreichischen Protestantismus gewann die Stadt zur Zeit der Glaubenskriege Bedeutung als intellektuelles Zentrum, wozu nicht zuletzt die 1574 nach Linz verlegte evangelische Landschaftsschule beitrug. $\mathrm{Zu}$ deren Lehrern hatten zeitweilig so bedeutende Gelehrte wie der Historiker Hieronymus Megiser und der Musiktheoretiker Daniel Hitzler gezählt. Eng mit der Schule und ihren Lehrern verbunden war auch Johannes Kepler, der von 1614 bis 1626 als Landschaftsmathematiker in Linz wirkte. Hier ließ er 1615 seine Stereometria doliorum - das erste in der Donaustadt gedruckte Werk - erscheinen, und 1618 wurde in Linz mit dem Druck seines umfangreichsten Werkes, der Epitome Astronomiae Copernicanae, begonnen. Ein Jahr später folgte die Harmonice mundi (Linz 1619). Vom akademischen Niveau des Linzer Gymnasiums zeugen noch heute die reichen Bibliotheksbestände, die auf die der Schule angegliederte Bibliothek der Landstände zurückgehen.

Freilich war auch in Linz die erste Hälfte des 17. Jahrhunderts von konfessionellen Auseinandersetzungen überschattet. Seit 1600 suchte die Gesellschaft Jesu, die Stadt zum alten Glauben zurückzuführen. Bereits 1619 taucht Keplers Epitome Astronomiae Copernicanae auf dem Index der von der Heiligen Congregation verbotenen Schriften auf. Im Zuge der Gegenreformation war auch die protestantische Landschaftsschule zunächst geschlossen, dann wiedereröffnet, 1624 endgültig suspendiert und 1629 mit der zwanzig Jahre zuvor gegründeten Lateinschule der Jesuiten vereint worden. ${ }^{4}$ Mit dem Neubau des Kollegiengebäudes wurde 1669 der sechsklassige Lehrplan dieser Schule um einen dreijährigen, jeweils im November beginnenden philosophischen Studienkurs ergänzt, der die Schule insbesondere für die adlige Jugend attraktiver machen und den Besuch auswärtiger Universitäten vorbereiten, wenn nicht gar ersetzen sollte.

Damit besaß nun auch Linz die Voraussetzungen, jenes umfassende Lehrangebot bereitzustellen, wie es die Ratio studiorum ${ }^{45}$ von 1599

44 Vgl. Lenzenweger (wie Anm. 34).

45 Ratio studiorum et Institutiones scholasticae Societatis Jesu, Bd. II, hrsg. von G. M. 
allen Jesuitenkollegien vorgeschieben hatte: dreijährige Studia altiora nach Abschluß der Lateinschule, wovon das erste Jahr der Logik und allgemeinen Wissenschaftslehre vorbehalten war; im zweiten Jahr dann die Aristotelische Pbysica, das erste Buch von De generatione et corruptione, die Meteorologica und aus De caelo die Lehre von den Elementen und der Substanz des Himmels, dazu Euklidische Geometrie; im dritten Jahr schließlich Metaphysik, Ethik und 'Psychologie' nach den Aristotelischen Büchern De sensu und De anima. Die internationale Organisation des Ordens und ein routinemäßiger Austausch des Lehrpersonals zwischen den Kollegien der einzelnen Ordensprovinzen - wo überall nach ähnlichen Methoden und Lehrbüchern vorgegangen werden konnte, solange Latein Unterrichtssprache war - hatten die Jesuiten im 17. Jahrhundert zu den Lehrmeistern des katholischen Europa werden lassen. Was die Effizienz des Unterrichts und den Anteil der formalen intellektuellen Bildung anging, mußten auch die Gegner des Ordens das hohe akademische Niveau seiner Schulen anerkennen. Besondere Verdienste hat sich die Gesellschaft Jesu bekanntlich auf dem Gebiet der mathematischen Wissenschaften erworben, zu denen damals auch Astronomie und Optik zählten. Gleichwohl blieb der fachwissenschaftliche Unterricht an den Jesuitenkollegien stets einem Ideal von Allgemeinbildung verpflichtet, das dem Spezialistentum wenig Raum ließ. Die naturphilosophische Ausrichtung der Schulen war von der Metaphysik des spanischen Gelehrten Petrus Fonseca bestimmt, dessen Werke sich auch in den Universitäten des protestantischen Deutschland größter Wertschätzung erfreuten. ${ }^{46}$ Die Stärke des von den Jesuiten vorgetragenen Aristotelismus lag dabei darin, daß er für Neues durchaus aufnahmefähig war, einen anpassungsfähigen Eklektizismus dem starren System vorzog und sich auch nicht scheute, strittige Punkte der peripatetischen Lehre beim Namen zu nennen. ${ }^{47}$

In Linz sollten dem Lehrplan fü- die höheren Studien zufolge im ersten Jahr Logica, im zweiten dazu Pbysica und Mathesis, im dritten schießlich Metaphysica, Etbica und Moraltheologie einschließlich der Grundzüge des Kanonischen Rechts vorgetragen werden. ${ }^{48}$ Eigene Lehr-

PACHLER ( Monumenta Germaniae Paedagogica », 5), Berlin 1887, S. 223-481, hier bes. S. 328-344.

46 Vgl. M. WUndT, Die deutsche Schulmetaphysik des 17. Jabrhunderts (« Heidelberger Abhandlungen zur Philosophie und ihrer Geschichte », 29), Tübingen 1939, bes. S. 40-45; dazu auch P. PETERSEN, Geschichte der aristotelischen Philosophie im protestantischen Deutschland, Leipzig 1921.

${ }^{47}$ Vgl. J. L. Heilbron, Electricity in the 17th and 18th Centuries: A Study of Early Modern Physics, Berkeley-Los Angeles-London 1979, S. 108-112.

$48 \mathrm{Vgl}$. LeNZENWEger (wie Anm. 34), S. 48-52 und 66-67. 
kanzeln für diese Fächer bestanden jedoch nicht; vielmehr begleitete der gleiche Professor, wie an den Jesuitenkollegien üblich, seine Studenten während der gesamten Dauer ihrer höheren Studien, dozierte also im ersten Jahr vornehmlich Logik, im zweiten Naturlehre und im dritten schließlich Metaphysik. Vielfach - wie auch im Falle Reinzers unterrichtete er zuvor noch Ethik. Leider sind die Einzelheiten des Lehrplanes nicht bekannt, da diesbezügliche Archivalien verloren sind, ${ }^{49}$ doch scheint es, als habe die mathematisch-physikalische Schwerpunktsetzung, für die die Schulen der Gesellschaft Jesu zumal in Frankreich so berühmt waren, in der österreichischen Ordensprovinz keine besondere Rolle gespielt, zumal hier ein besonders rascher Wechsel der Lehrkräfte einer fachwissenschaftlichen Vertiefung im Wege stand.$^{50}$

Nachdem die Schule auf Antrag der Landstände im Jahre 1674 von Kaiser Leopold I. das Privileg erlangt hatte, Baccalaureat und Magisterium zu verleihen, und Linz damit formal den Jesuitenhochschulen der österreichischen Ordensprovinz in Wien, Graz, Kaschau (Kosice) und Tyrnau (Trnava) gleichgestellt worden war, erreichten Einzugsgebiet, Ansehen und Frequenz der Anstalt im ersten Jahrzehnt des 18. Jahrhunderts mit etwa 170 Studenten ihren Höhepunkt. Im Studienjahr 1697/ 98, dem Entstehungsjahr der Meteorologia philosopbico-politica, waren 54 Studenten für das erste Jahr (Logik), 55 für das zweite Jahr (Physik) und 28 für das dritte Jahr (Metaphysik) immatrikuliert. ${ }^{51}$ Das Hauptkontingent stellten stets nichtadelige Bürgerssöhne aus dem Lande ob der Enns, daneben in größerer Zahl auch junge Adelige und Ordensgeistliche. Eine Besonderheit des Linzer Akademischen Gymnasiums bestand darin, $\mathrm{da} ß$ es - im Unterschied zu den Gymnasia Altiora in Klagenfurt, Agram (Zagreb), und Görz (Gorizia) - in begrenztem Umfang auch ein fachwissenschaftliches Studium nach Art der Universitäten ermöglichte, und zwar insbesondere in Theologie und Kanonischem Recht, wofür von 1671 an eigene Lehrkanzeln bestanden, denen 1696 als laizistische Neuerung eine Professur für Zivilrecht hinzugefügt wurde. Aber auch Fachstudenten der Metaphysik, der Naturlehre oder der Logik wurden, gelegentlich sogar als Externe, zum Studium zugelassen. Vom Recht, aka-

49 Freundliche Auskunft des Oberösterreichischen Landesarchivs Linz.

50 Siehe F. DE DaInville, L'enseignement scientifique dans les collèges des Jésuites, in Enseignement et diffusion des sciences en France au XVIII' siècle, hrsg. von R. TATON ( Histoire de la pensée », 11), Paris 1964, S. 27-65. Zu den Verhältnissen in der österreichischen Ordensprovinz siehe F. X. EgGERSDORFER, Die Pbilosophisch-Theologische Hocbschule Passau, Passau 1933, S. 129; nicht viel anders war es auch in Bayern, vgl. A. SEIFERT, Der jesuitische Bildungskanon im Lichte zeitgenössischer Kritik, "Zeitschrift für bayerische Landesgeschichte», 47, 1984, S. 43-75.

51 Lenzenweger (wie Anm. 34), S. 80. 
demische Grade zu verleihen, hat die Schule aber nachweislich keinen Gebrauch gemacht; denn für eine Entwicklung zum Universitätsrang fehlten ihr wohl doch die Voraussetzungen..$^{52}$ Der schulische und soziale Kontext ist damit umrissen.

\section{Scientia Meteororum}

Als Teilgebiet der alten Naturlehre und Naturphilosophie hat die gelehrte Beschäftigung mit den atmosphärischen Erscheinungen über mehr als 2000 Jahre im großen und ganzen die Form bewahrt, die Aristoteles diesem Wissensgebiet gegeben hatte. Meteorologie als Wissenschaft bedeutete damit auch und in erster Linie, die alten Fragen nach causa materialis, formalis, efficiens und finalis zu stellen und die Phänomene, die zwischen Himmel und Erde zu beobachten waren, nach den Kategorien von Substanz und Akzidenz, Form und Materie, Akt und Potenz zu analysieren. Den Gegenstandsbereich der Meteorologie hatte Aristoteles in seinen Meteorologicorum libri IV, der ältesten erhaltenen wissenschaftlichen Darstellung dieses Gebietes, folgendermaßen definiert:

Sie umfaßt alle die Geschehnisse, die sich auf natürliche Weise [...] vollziehen, und zwar besonders in dem der Gestirnsphäre benachbarten Raum, z.B. Milchstraße, Kometen und die Phänomene, die auf Entzündung, verbunden mit Bewegung, beruhen; dazu alle, die wir der Luft und dem Wasser als gemeinsame Vorgänge zuschreiben können; sodann noch im Hinblick auf die Erde, ihre Teile, ihre Arten und die Eigenschaften dieser Teile; woran sich die Betrachtung der Ursachen von Winden und Erdbeben schließt, sowie aller mit deren Bewegungsursachen in Zusammenhang stehenden Phänomene. ${ }^{53}$

An die Wissenschaft von den meteora, den « in der Schwebe " befindlichen Naturerscheinungen, der Bücher I-III schließt sich nach der traditionellen Anordnung der Aristotelischen Libri naturales als Buch IV der Meteorologie eine eher den chemischen Teilen von De generatione et corruptione zugehörende Studie stofflich-chemischer Vorgänge an, wodurch auch Prozesse der unbelebten Natur in den Lehrzusammenhang der Meteorologie hineingenommen wurden. Im Unterschied $\mathrm{zu}$ den 'chemischen' Körpern der Erdoberfläche, die als « vollständig Ge-

52 Ebenda, S. 53. Daher ist auch die Meteorologia philosophico-politica nicht als Inauguraldissertation anzusehen!

53 Aristoteles, Meteorologie, übers. von H. Strohm, 2. Aufl. («Aristoteles Werke», hrsg. von E. GrumaCH, Bd. 12), Berlin 1979, I.1., S. 9 (338b20-339a1). 
mischte » an allen vier Elementen Anteil hatten, galten die meteora im strengeren Sinne als unvollständige mixta, die neben den Elementarformen keine eigene substantielle Form besitzen und daher leicht ineinander übergehen oder wieder in die Elemente zerfallen sollten. Konzeptionell lagen der Aristotelischen Meteorologie folgende Theorien zugrunde: Die auf der Kosmologie des Eudoxos mit seinen homozentrischen Sphären basierende radikale Dichotomie in eine sublunare, Veränderungen unterworfene Region und den ewig unwandelbaren Himmel jenseits der Bahn des Mondes schuf eine radikale ontologische Differenz zwischen Astronomie und Meteorologie bzw. Physik. Sie war die Voraussetzung, um die Vorgänge in der Atmosphäre und auf der Erde rein naturwissenschaftlich zu erfassen, ohne auf abergläubische Vorstellungen oder auf den Einfluß der himmlischen auf die irdischen Phänomene rekurrieren zu müssen. Die Aristotelische Meteorologie hat also, zumal wenn man die Zeit ihrer Entstehung bedenkt, einen eminent rationalistischen, ja reduktivistischen Zug. In dieses kosmologische Schema hatte Aristoteles die vier empedokleischen Elemente Feuer, Luft, Wasser und Erde samt den zugehörigen, paarigen Primärqualitäten warm/kalt und feucht/trocken eingeordnet. Unter der Annahme zweier Arten von Ausdünstungen oder anathymiaseis und einer besonderen Luftwirbel-Theorie konnte er nun sämtliche Erscheinungen der Luftregion als Folge der Einwirkung der Sonnenwärme auf Wasser oder Erde erklären. ${ }^{54}$ Wolken und Niederschläge, Gewitter und Winde, ja sogar Sternschnuppen und Kometen, Erdbeben und Metallogenese waren damit auf gemeinsame, aus gewöhnlicher Erfahrung abgeleitete Ursachen zurückgeführt. Auch die optischen Phänomene der Atmosphäre sowie hydrographische Fragen gehörten in den Umkreis der Aristotelischen Meteorologie.

Obgleich in ungewöhnlich hohem Maße auf Erfahrungstatsachen aufbauend, war die Meteorologie des Aristoteles eine weitgehend deduktiv vorgehende, theoretische Wissenschaft. Mit dem seit jeher populären Genre der Wetterprognostik, das sich, was die gelehrt-empirische Tradition angeht, von Theophrasts De signis tempestatum und De ventis herleitete, hatte sie nicht viel gemein. Allerdings war ihr relativ einfaches theoretisches Fundament nur begrenzt imstande, neue Beobachtungstatsachen $\mathrm{zu}$ integrieren. So waren bereits im Mittelalter einzelne

54 Für einen Überblick über die Aristotelischen Vorstellungen vgl. H. H. Frisinger, The History of Meteorology to 1800 ( « American Meteorological Society, Historical Monograph Series»), New York 1977, bes. S. 15-23; I. DürING, Aristoteles: Darstellung und Interpretation seines Denkens, Heidelberg 1966, S. 385-399; sowie allgemein das noch immer unverzichtbare Werk von O. GILBERT, Die meteorologischen Theorien des griechischen Altertums, Leipzig 1907. 
Bereiche der meteorologischen Optik, insbesondere das Problem der atmosphärischen Lichtbrechung und der Entstehung des Regenbogens, ausgegliedert und zu Teilgebieten der geometischen Optik gemacht worden, wo sie, vom starren Theorierahmen der aristotelischen Meteorologie befreit, theoretisch wie experimentell wesentlich rascher vorankamen. Es überrascht kaum, daß das traditionelle Lehrgebäude der Meteorologie davon nur wenig berührt wurde. Im Gegenteil, von der Editio princeps im Jahre 1474 bis in die Mitte des 17. Jahrhunderts hat man mehr als 135 Textausgaben der Aristotelischen Meteorologie und ganze 156 Kommentarwerke gezählt, ${ }^{55}$ darunter auch auflagenstarke Kompendien und populäre Ausgaben in den Landessprachen. Die Astrometeorologie der Renaissance mit ihren Wetterregeln sowohl magisch-abergläubischer als auch empirischer Provenienz, die im wesentlichen von neuplatonischen Vorstellungen über eine Sympathie-Antipathie-Beziehung zwischen Makrokosmos und atmosphärischem Geschehen zehrte, hat sich gegen die Vorherrschaft der aristotelischen Meteorologie zumindest im Lehrbetrieb der Schulen und Hochschulen kaum durchsetzen können. Im gelehrten Streit der Schulen, von dem Werke wie Johann Garcaeus' astrologisch gefärbte Meteorologia (Wittenberg 1568) oder Wolfgang Meurers streng peripatetische Meteorologia (Leipzig 1587) und seine Commentarii meteorologici ex solidis philosophiae Aristotelicae fundamentis deducti (Leipzig 1592) zeugen, sollte sich letztlich ein gemäßigter Aristotelismus durchsetzen, der in der Lage war, auch neueres Erfahrungswissen zu inkorporieren. An der Schwelle, die die alte deduktiv-spekulative Meteorologie von der physikalischen Untersuchung atmosphärischer Phänomene trennt, steht schließlich René Descartes' Schrift Les Météores, die dieser selbst als Beleg für die Leistungsfähigkeit seiner im Discours de la méthode (Paris 1637) vorgestellen naturwissenschaftlichen Methodologie verstanden wissen wollte. ${ }^{56}$ Gleichwohl ist gerade die Cartesische Meteorologie ein gutes Beispiel für ćie relative ' Rückständigkeit' jenes Wissenschaftszweiges, mißt man ihn an den zeitgenössischen Fortschritten in Astronomie und Physik.

$55 \mathrm{Vgl}$. G. Hellmann, The Dawn of Meteorology, "Quarterly Journal of the Royal Meteorological Society », 34, 1908, S. 223-227; sowie ders., "Bibliographie der gedruckten Ausgaben, Ubersetzungen und Auslegungen der Meteorologie des Aristoteles », in HellmanN (wie Anm. 7).

$56 \mathrm{Vgl}$. dazu E. Gilson, Météores cartesiens et météores scolastiques, in ders., Etudes sur le rôle de la pensée médiévale dans la formation du système cartésien ("Etudes de philosophie médiévale », 13), Paris 1951, S. 102-137. 


\subsection{Meteorologie im 17. Jabrbundert}

Mit der zunehmenden Instrumentalisierung der Naturbeobachtung, der Entwicklung der experimentellen Methodologie und der Quantifizierung der beobachteten Phänomene leitete das Zeitalter der Naturwissenschaftlichen Revolution auch in der über nahezu zweitausend Jahre nur wenig veränderten Meteorologie einen tiefgreifenden Struktur- und Gegenstandswandel ein. Seine Auswirkungen wurden freilich erst in der zweiten Hälfte des 18. Jahrhunderts sichtbar.

Ausgangspunkte dieses Wandels waren die Einführung des Thermometers ${ }^{5}$ durch den Schülerkreis Galileis sowie das 1643 von Vincenzo Viviani durchgeführte Vakuumexperiment Evangelista Torricellis, das bald darauf von Marin Mersenne und Blaise Pascal wiederholt und in seiner einzigartigen Bedeutung für die physikalische Theorie erkannt wurde.$^{58}$ Für die Fortentwicklung der Thermometrie und Barometrie ist dann die Florentiner Accademia del Cimento von großer Wichtigkeit gewesen, deren Saggi di naturali esperienze ${ }^{59}$ das experimentalphysikalische Forschungsprogramm jener Gesellschaft in ganz Europa bekanntmachten. In der Tat war mit dem Nachweis der physikalischen Realität des Vakuums eines der zentralen Dogmen der aristotelischen Naturphilosophie und Materielehre hinfällig geworden. Es hätte kaum der barockspektakulären Demonstrationen des Magdeburger Bürgermeisters Otto von Guericke ${ }^{60}$ vor den 1654 auf dem Reichstag zu Regensburg versammelten Potentaten bedurft, um jedermann deutlich zu machen, daß mit dem Vakuum ein experimentum crucis wider den naturwissenschaftlichen Aristotelismus geglückt war. Mit Torricellischer Säule, Luftpumpe, pneumatischer Wanne und dergleichen Vorrichtungen mehr war die Luft zum Gegenstand der Experimentalphysik geworden und den Methoden der Hydrostatik und Aerodynamik zugänglich gemacht.

Wir wissen inzwischen, daß gerade in der Frühzeit die zu Unrecht so häufig geschmähten Jesuiten wesentlichen Anteil an der Entwicklung

$57 \mathrm{Vgl}$. W. E. Knowles Middleton, A History of the Thermometer and its Use in Meteorology, Baltimore 1966.

58 Vgl. ders., The History of the Barometer, Baltimore 1964.

59 Florenz 1667, 21691 u.ö.; engl. London 1684; lat. Leiden 1731; frz. Lausanne 1754-Dijon 1755; vgl. dazu W. E. KNowles Middeton, The Experimenters: $A$ Study of the Accademia del Cimento, Baltimore-London 1971.

60 Siehe O. von GUERICKE, Experimenta nova (ut vocantur) Magdeburgica de vacuo spatio, Amsterdam 1672; dt. als: Otto von Guerickes Neue (sogenannte) Magdeburger Versuche über den leeren Raum, übers. u. hrsg. von H. Schimank, Düsseldorf 1968. 
der Experimentalphysik hatten. ${ }^{61}$ In der Optik, der Mechanik, der Elektrizitätslehre und der Erforschung des Magnetismus haben Jesuiten bedeutende Beiträge geliefert und - wichtiger noch - diese Gebiete als erste in den Unterricht ihrer Schulen und Kollegien eingeführt. Erinnert sei bloß an den enzyklopädischen Athanasius Kircher und seinen Schüler Caspar Schott, den Würzburger Mathematik- und Physikprofessor, der nicht nur Guerickes Magdeburger Experimente in seiner Mechanica bydraulico-pneumatica (Würzburg 1657) erstmals im Druck bekannt gemacht, sondern auch in Werken wie seiner Magia universalis (Würzburg 1657-1659), seiner Pbysica curiosa (Würzburg 1662) und seiner Technica curiosa (Würzburg 1664) das gesamte Spektrum zeitgenössischer physikalischer Experimentierkunst und Experimentierlust entfaltet hatte.

Bemerkenswert ist nun - und eben dies hat die Geschichtsschreibung der Meteorologie bisher nicht recht erkannt - daß die Flut neuer Ergebnisse, Instrumente und Methoden, die das 17. Jahrhundert hervorbrachte, keineswegs automatisch eine Transformation der alten Meteorologie nach sich zog oder dies auch nur vermocht hätte. Denn diese zielte auf Fragen und Gegenstände, die auch mit den neuen Verfahren nicht zu erforschen gewesen wären. Die Folge war, daß sich aus jener weitgespannten Wissenschaft von den Dingen zwischen Himmel und Erde Teilbereiche ausgrenzten, die eigene Forschungs- und Fragetraditionen begründeten, dann zu Teilbereichen der neuzeitlichen Physik wurden und erst von dort aus sehr viel später wieder auf die Meteorologie zurückwirken sollten. Es ist darum kein Zufall, daß Johann Christoph Sturm, Mathematik- und Physikprofessor an der Universität Altdorf, im Collegium experimentale sive curiosum (Nürnberg 1701), das aus seinem seit 1672 gehaltenen Experimentalkolleg, der ersten Vorlesung über Experimentalphysik an einer europäischen Universität, ${ }^{62}$ hervorgegangen war, bei der Darstellung der barometrischen, thermometrischen, hydrostatischen und optischen Versuche den ursprünglichen Bezug zur Meteorologie und Wetterkunde kaum noch erkennen läßt: kein Wort über die Ursachen von Wind und Regen, kein Versuch, die Wolkenbildung und die Herkunft des Quellwassers aufgrund der neuen Erkenntnisse zu deuten. Selbst im Index des Collegium experimentale fehlt das Stichwort meteora.

Um so mehr mag es überraschen, neben der modernen experimentalphysikalischen Richtung, die auf meßbare Größen und gesetzmäßige

61 Vgl. Heilbron (wie Anm. ‘7), bes. S. 101-114.

$62 \mathrm{H}$. Schimank, Zur Gescbicbte der Physik an der Universität Göttingen vor Wilbelm Weber, « Rete », 2, 1974, S. 207-252, hier S. 208-209. 
Zusammenhänge aus war, die alte Wissenschaft von den Meteoren wenn auch in modernisiertem Gewande fortbestehen zu sehen. Zwar trat die überkommene Form der Kommentierung der Meteorologicorum libri IV kaum noch in Erscheinung, doch blieben Struktur und Konzeption der Aristotelischen Meteorologie als Teilgebiet der Physica, d.h. vornehmlich auf den Naturkörper und seine substantiell-akzidentiellen Veränderungen gerichtet, auch weiterhin erhalten. Den engen Zusammenhang von $\mathrm{Me}$ teorologie und Materielehre macht das Lexikon philosophischer Begriffe des Greifswalder Professors Johannes Micraelius von 1653 deutlich, wenn es heißt:

Meteora, corpora imperfecte mixta et variis impressionibus mentes hominum percellentia. Meteorologia est doctrina de meteoris. Meteororum materia est exhalatio sive spirituosa, quae dicitur xarvòs seu fumus; sive crassior et humidior, et dicitur vapor seu $\alpha \tau \mu i \zeta$. Meteora sunt vel ignea, vel aquea, vel aërea, vel emphatica. ${ }^{63}$

$\mathrm{Zu}$ den feurigen Meteoren, deren Zustandekommen einer entzündlichen Materie zugeschrieben wurde, die in der Nähe der Feuersphäre oder durch antiperistatis- Wirkung der umgebenden Kälte in Brand gerät, zählten alle Flammen- und Lichterscheinungen des Himmels einschließlich Blitz und Donner. Zu den luftigen Meteoren zählten die Winde, zu den wässrigen Regen, Nebel, Reif und alle Formen von Niederschlag, zu den scheinbaren schließlich Luftspiegelungen, Nebensonnen, Wolkenfärbungen und der Regenbogen.

Wenn die letzteren, die meteora emphatica, bei Micraelius von den Hydrometeoren abgetrennt sind, so deutet sich darin bereits die Ausgrenzung der rein optischen Phänomene aus der Meteorologie an, die als Pbysica ja eigentlich von corpora handelt. Die gleiche Scheidung begegnet uns auch $1738 \mathrm{im}$ Zedlerschen Universallexikon, das den Leser von «Meteorologie » auf $~ " L u f f t=$ Zeichen ${ }^{64}$ verweist und diese zunächst in apparentia (Regenbogen, Halo, Nebensonnen etc.) und vera unterteilt, welch letztere ganz traditionell in aquea, aërea und ignea zerfallen. Lediglich die Erdbeben als unterirdische Vorgänge mochte Zedler nicht mehr dem sublimen Bereich der meteora zurechnen.

Welches die Fragestellungen der wissenschaftlichen Meteorologie noch zu Beginn des 18. Jahrhunderts waren, verrät das berühmte Lexikon des gelehrten Hugenotten und Cartesianers Etienne Chauvin, Mitbegrün-

63 J. Micraelius, Lexicon philosopbicum terminorum philosophis usitatorum [1653], 2. Aufl., Stettin 1662, Sp. 772-773.

64 Zedler (wie Anm. 40), 18, 1738, Sp. 1051. 
ders der Berliner Akademie der Wissenschaften und eines der rührigsten Mitglieder ihrer medizinisch-physikalischen Klasse:

Meteora communiter dicuntur corpora imperfectè mixta, ideò quòd substantiales formas, praeter elementorum, ex quibus generantur, nullas habeant, facilè aliam naturam induant, ac in pristina elementa resolvantur. Verùm Recentiores nonnulli volunt meteora dici non modò corpora, sed et corporum effectus atque accidentia, quae in aëre generantur et producuntur; etenim non omnia meteora esse corpora, sed horum solùm quaedam phaenomena patet attendenti, tonitru siquidem Iris, etc. haud dici possunt corpora. Addunt iidem, non omnia meteora imperfectè mixta observari, v.g. mel, manna; imò quaedam ex corporibus non simplicibus, sed perfectè mixtis, v.g. exhalationibus aqueis et terreis generari; quin nec ex solis elementis produci, sed non rarò ex ipsis mixtis, proût constat attendenti. ${ }^{65}$

Chauvin weist dann nach, daß die peripatetische Lehre, wonach allein wässrige und erdige Ausdünstungen das Zustandekommen der atmosphärischen Erscheinungen bewirkten, unzureichend sei, führt Beispiele für die Beteiligung erdiger und metallischer Stoffe an, begründet die Suspension der Wolken ${ }^{66}$ gut cartesisch mit dem Ausweichen der leichteren Teilchen vor dem Druck der schwereren in dem die Erde umgebenden Materiewirbel, um schließlich die Arten und Ursachen der Verdichtungen zu besprechen, die wässrige oder feurige Meteore hervorbringen.

Nach wie vor ist also das Interesse an Meteorologie vom Interesse an der Beschaffenheit der meteorologischen corpora und ihren Veränderungen geprägt; von Temperatur und Luftdruck ist bei Chauvin nicht die Rede. Dabei ist er durchaus kein Beispiel für die notorische Rückständigkeit der Lexikographen, ${ }^{67}$ hat er doch selbst aktiv am wissenschaftlichen Leben teilgenommen und sogar eine Abhandlung De nova circa vapores bypothesi zu den Miscellanea Berolinensia ${ }^{68}$ beigesteuert. Die meteorologische Fachliteratur der Zeit bestätigt den Befund vollkommen.

Es sind im wesentlichen vier Autoren, die die wissenschaftliche Meteorologie des 17. Jahrhunderts repräsentieren: Der Genuenser Jesuitenmathematiker Niccolò Cabeo (1586-1650), der Löwener Philosophieprofessor Libert Froidmont (1587-1653), der Jesuit, Philosoph und Mathe-

65 S. Chauvin, Lexicon Pbilosophicum [1692], 2. Aufl., Leeuwarden 1713 (Reprint Düsseldorf 1967), S. 403-404.

${ }^{66}$ Zum Stellenwert dieser Frage vgl. W. E. Knowles Middleton, $A$ History of the Theories of Rain and other Forms of Precipitation ( Oldbourne History of Science Library »), London 1965, S. 43-62.

67 Für die spätere Zeit vgl. hierzu A. HugHEs, Science in English Encyclopaedias, 1704-1875 - III: Meteorology, "Annals of Science », 9, 1953, S. 233-264.

68 Miscellanea Berolinensia, 1 (1710), S. 120-122. 
matiker Honoré Fabri (1607-1688), schließlich der nachmalige Sekretär der Académie des Sciences Jean-Baptiste Duhamel (1623-1706).

Niccolò Cabeos vier umfängliche Folianten füllende In quatuor libros Meteorologicorum Aristotelis commentaria (Rom 1646) ${ }^{69}$ sprengen bereits die klassische Form des Aristoteleskommentars und weiten sich aus zur allgemeinen Naturphilosophie und Naturlehre, in deren Zentrum Cabeo die Meteorologie als dasjenige Teilgebiet der aristotelischen Physik stellte, das wegen seines eminent empirischen und praktischen Gehaltes am ehesten seinen Vorstellungen von einer neuen terrestrischen Physik entsprach. Bei aller Kritik, die der Autor am Aristotelismus übte, galt diese jedoch vor allem dem Ziel, die wahre Lehre des Philosophen wiederherzustellen und die Astrometeorologie und Renaissancemagie mit ihrer Auffassung von einer sympathetischen actio in distans zurückzudrängen.

Auch Libert Froidmonts häufig wiederaufgelegte Meteorologicorum libri VI (Löwen 1627), ${ }^{70}$ deren Autorität noch Zedler gelten ließ ${ }^{71}$ sind ein Werk, das sich nur wenig von der peripatetischen Lehrtradition entfernt. Die sechs Bücher behandeln die Meteore im allgemeinen, die Feuermeteore, die Kometen, Winde und Erdbeben, die Hydrometeore einschließlich der Meere und ihrer Gezeiten ${ }^{72}$ der Flüsse und Quellen, schließlich die scheinbaren Meteore. Unter den letzteren wird auch der Regenbogen behandelt, doch ohne auf die inzwischen verfügbaren optischen Erkenntnisse vom Strahlengang im Regentropfen einzugehen: Hier wirkte sich einmal mehr die traditionelle Trennung von Physik und Mathematik/Optik mit dem Aristotelischen Verbot der Metabasis von einem Wissenschaftsgebiet in ein anderes verhängnisvoll aus. Zögernd nur finden die Ergebnisse der neueren Astronomie Eingang: So wird die Aristotelische Theorie der Kometen ${ }^{73}$ abgelehnt, wonach diese aus Feuerkeimen entstehen, die die Reibung der untersten Himmelssphäre in der obersten, feurig-trockenen Luftschicht erzeugt, wo sie auf entzündliche Ausdünstungen der Erde treffen. Bereits an dem großen Kometen des Jahres 1577 hatte Tycho Brahe ja zeigen können, daß dieses

69 Siehe auch L. Thorndike, A History of Magic and Experimental Science, Bd. VII, New York 1958, S. 422-424.

70 Benutzte Ausgabe: L. Fromondus, Meteorologicorum libri VI, ed. altera auctior et correctior, Löwen 1646. Siehe auch THORNDIKE (wie Anm. 69), VII, S. 53-54.

71 Zedler (wie Anm. 40), 18, 1738, Sp. 1051.

72 Zur Gezeitentheorie Froidmonts vgl. D. Burger, Two Dissertations on the Tides in the 17th Century, "Janus", 46, 1957, S. 41-45, der ihn zu Unrecht « out and out scholastic " nennt.

73 ARIstoteles, Meteor I. 7. (344a5 ff). 
Phänomen weit jenseits der Mondsphäre zu lokalisieren sei. Auch Froidmont nennt deshalb die fehlende Parallaxe das entscheidende Argument gegen die überkommene Auffassung. Da aber Sternschnuppen und Kometen gemeinhin als verwandte Erscheinungen galten und die aristotelische Tradition den Schweif des Kometen als optisches Brechungsphänomen an atmosphärischer Materie verstand, schien auch die ' astronomische ' Erklärung nicht ganz befriedigend.

Ein Charakteristikum der Froidmontschen Meteorologie ist die reiche Verwendung literarischer, mythologischer und biblischer Beispiele, die freilich gelegentlich die Grenze des Plausiblen überschreiten, so etwa, wenn es um die Frage geht, ob die Dunst- und Feuersäule, die dem Volke Israel auf seinem Weg durch die Wüste vorausging, ${ }^{74} \mathrm{zu}$ den feurigen Meteoren gerechnet werden könne, was der Verfasser mit einer wunderlichen Theorie über deren Zustandekommen bejaht. Dies ist nicht untypisch für seine generelle Tendenz, dämonologisch-animistische und abergläubische Vorstellungen, die gerade auf dem Gebiet der Meteorologie so überreichlich Nahrung fanden, mit den Mitteln aristotelischer Naturphilosophie und Naturwissenschaft zu bekämpfen. Besonders scharf ging Froidmont mit der neuplatonischen Kosmologie und deren Lehre von Korrespondenzbeziehungen zwischen himmlischer und Erdenwelt ins Gericht. Deshalb wurden auch Keplers astrologische Neigungen als Rückfall in magische Vorstellungen kritisiert.

Obgleich überzeugter Aristoteliker und Verfechter des alten Weltbildes - wir besitzen von ihm eine Schrift mit dem Titel Ant-Aristarchus sive orbis terrae immobilis liber unicus (Antwerpen 1631) - war Froidmont durchaus mit der neueren Literatur vertraut, und auch eigene Naturbeobachtungen flossen in seine Darstellung ein. Hinzu kommt eine dem Aristotelismus in Grunde fremde Tendenz zu physikotheologischen Betrachtungen, die seit dem ausgehenden 17. Jahrhundert in den Werken eines John Ray, eines William Derham und eines Johann Albert Fabricius so große Bedeutung - auch für die Naturwissenschaften - gewinnen sollten. ${ }^{75}$ Bei Froidmont ist das physikotheologische Anliegen durchaus konsistent mit der Zurückweisung von Magie und Aberglauben. Nicht als astrale Emanationen, dämonische Blendwerke oder bedeutungsvolle Vorzeichen sollten die atmosphärischen Erscheinungen gewertet werden,

74 Exod. 13, 21-22.

$75 \mathrm{Vgl}$. dazu U. KrolzIK, Das physikotheologische Naturverständnis und sein Einfluß aus das naturwissenschaftliche Denken im 18. Jabrbundert, « Medizinhistorisches Journal ",
15 , 1980, S. 90-102. 
sondern als Ausweis der Güte und Voraussicht des Schöpfers. In Froidmonts Vorrede an den Leser heißt es:

Scriptura etiam sacra [...] Meteorologiam totam ad Dei laudes, id est, ut homines ex operum istorum et totius naturae contemplatione Creatorem laudent, saepe excitat. Nemo autem altiùs et impensiùs laudare potest, quam Meteorologistes, et qui optimè ea intelligit.

$\mathrm{Ob}$ die von Froidmont gleichfalls verhießene utilitas meteorologischer Kenntnisse im Krieg, im Feldbau und im Handel ebenso leicht aus seinem Werke folgte, muß dahingestellt bleiben; denn die aristotelische Meteorologie hat niemals ein Instrument zur Wetterprognostik sein wollen.

Ein völlig anderer Geist herrscht in den Schriften des gelehrten Jesuiten Honoré Fabri, der an verschiedenen südfranzösischen Kollegien unterrichtet und extensiv publiziert hatte, und schließlich in Rom das Amt des Großinquisitors übernahm. ${ }^{76}$ Innerhalb der naturwissenschaftlichen Literatur der Jesuiten steht Fabri für den Übergang vom Aristotelismus zur Entwicklung eigener, eklektischer Systeme. ${ }^{\pi}$ Trotz frommen Festhaltens am Hylemorphismus hat er gerade in der Bewegungslehre eindeutig antiaristotelische Positionen bezogen. Das heliozentrische Weltbild, die Ringe des Saturn, die Theorie der Gezeiten, das waren die Fragen, die ihn beschäftigten. In der Materietheorie übernahm Fabri von Descartes und Gassendi korpuskulare Vorstellungen. Mehrfach geriet er in Konflikt mit der Kirche. Von späteren Autoren wurde insbesondere die Windlehre aus dem sechsten Traktat seiner Physik ${ }^{78}$ als beispielhaft herausgestellt. ${ }^{79}$

Steht Fabri noch auf der Schwelle von der alten zur neuen Physik, so begegnet uns in dem Naturwissenschaftler, Philosophen und Theologen Jean-Baptiste Duhamel, ${ }^{80}$ der der erste Secrétaire perpétuel der $\mathrm{Pa}$ riser Académie des Sciences werden sollte, der bedeutendste Exponent einer rein cartesischen Meteorologie. Seine De meteoris et fossilibus libri II (Paris 1660) galten fast ein Jahrhundert hindurch als das Stan-

76 Vgl. E. A. FellmanN, in Dictionary of Scientific Biography, 4, 1970, S. 505-507.

77 Vgl. Heilbron (wie Anm. 47), S. 110.

$78 \mathrm{H}$. FABRI, Physica id est scientia rerum corporearum in $X$ tractatus distributa, Bd. I-V, Lyon 1669-1671.

79 So D. G. MorhoF, Polybistor literarius, philosopbicus et practicus, hrsg. von J. Moller, 2. Aufl., Lübeck 1714, Bd. II, S. 381: " Nemo, quam Hon. Fabri, magis planâ viâ procedit, minusque in hâc doctrinâ extra viam rapitur ".

$80 \mathrm{Vgl}$. P. Costabel, in Dictionary of Scientific Biography, 4, 1971, S. 221-222; A. InGoLd, in Dictionnaire de théologie catholique, 6, 1920, Sp. 2039-2041. 
dardwerk des Faches schlechthin. Daniel Georg Morhofs Polybistor schreibt über ihn:

praestantissimus vir J. Bapt. Du Hamel, Philosophus et diligentissimus et acutissimus, qui meteororum et fossilium naturam conjunctim explicuit in suo de meteoris et fossilibus libro [...], qui ad meteororum naturam probè pernoscendam adeo aptus est, ut nullus liber majorem lucem accendat. ${ }^{81}$

Das solchermaßen gepriesene Werk, das im ersten Buch die meteora als mixta imperfecta, im zweiten die Gesteine, Mineralien und Metalle als mixta perfecta behandelt, hat die Form eines gelehrten Dialogs zwischen Theophilus, einem Anhänger der alten Philosophie, Simplicius, dem klassischen idiota, und Menander, dem Vertreter des Cartesianismus. ${ }^{82}$ Erklärtes Ziel des Autors war, die Vorzüge der cartesischen Philosophie zu erweisen; denn auch wenn Aristoteles «philosophorum omnium est longè princeps », so gebe es doch keinen Grund, ihm in allem und jedem zu folgen. ${ }^{83}$ Gassendi und Descartes ( $"$ Cartesius noster ») gehören denn auch zu den am häufigst zitierten Autoren aus einer weiten Palette gelehrter Literatur unter Einschluß der Naturwissenschaftler aus jüngerer Zeit.

Selbst was den Aufbau des Werkes angeht, ist der Bruch mit der Tradition der Aristotelischen Meteorologie augenfällig. Wie üblich geht es zunächst um Materie und Ursachen der meteora; besonders eingehend wird dabei die Frage erörtert, welchen Einfluß das Feuer im Erdinneren auf seismische, vulkanische und atmosphärische Erscheinungen hat. Eine große Rolle spielen hierbei mechanistische und auch 'chemische' Erklärungen, die an den paracelsischen spiritus nitro-aëreus erinnern. ${ }^{84}$ Dann geht es um hydrographische und ozeanographische Fragen. Das Auftreten von Quellen im Hochgebirge zu erklären, war eines der strittigsten Probleme im Kontext der aristotelischen Meteorologie mit ihren nach Schwere und Leichtigkeit der Elemente geschichteten Luftregionen. Auch Ebbe und Flut werden erörtert, okkulte Einflüsse der Himmelskörper dabei ausgeschlossen und auf die Galileische Gezeitentheorie, insbesondere aber auf die Descartessche Erklärung durch Materiewirbel verwiesen. ${ }^{85}$ Die folgenden Kapitel befassen sich mit wässri-

81 Morhof (wie Anm. 79), II, S. 380-381.

82 Vgl. auch ThORNDike (wie Anm. 69), VIII, S. 204-207.

83 J. B. Du Hamel, De meteoris et fossilibus libri II, Paris 1660, S. 1.

84 Hierzu vgl. A. G. Debus, "The Paracelsian Aerial Niter», Isis 55 (1964), S. 43-61.

85 Duhamel (wie Anm. 83), S. 11-15, 23-27. 
gen und luftigen Meteoren, den Feuermeteoren und schließlich den optischen Phänomenen der Luft, besonders Regenbögen und Haloerscheinungen. Hier ist die Abhängigkeit von Descartes' Optik besonders deutlich; Strahlengang und das Zustandekommen der Farben sind geometrisch und physikalisch erklärt sowie im Bilde verdeutlicht. Damit ist Duhamels De meteoris et fossilibus das erste meteorologische Werk, das sich die Ergebnisse der neuen Optik zu eigen gemacht hat. Im Schlußkapitel De coloribus qui per trigonum crystallinum apparent deutet sich bereits die Ausgrenzung der meteorologischen Optik aus der Lehre von den atmosphärischen Erscheinungen und ihre Übertragung in den Kontext experimentalphysikalischer Untersuchungen an.

Es bedarf kaum der Erwähnung, daß Duhamel mit der naturwissenschaftlichen Literatur des 17 . Jahrhunderts vertraut war und seiner Darstellung die sonst übliche Vorliebe für Merkwürdiges und Wunderbares vollkommen fehlt. Für einen Cartesianer verstand es sich beinahe von selbst, daß die neue, physikalisch und kausalmechanisch vorgehende Meteorologie nicht länger die Argumente zu einem naturwissenschaftlichen Gottesbeweis hergeben konnte. Zwar hatten die Theologen seit der Patristik Himmels- und Wetterzeichen stets in besonderem Maße dazu benutzt, die providentia Gottes einsichtig, ja aus der sinnhaften Ordnung der Natur den Schöpfer selbst beweisbar zu machen; doch mit dem Durchbruch von der teleologischen zur mechanistisch-kausalen Betrachtungsweise und der radikalen Cartesischen Trennung zwischen res extensa und res cogitans war dies nun nicht länger möglich, ohne die Methoden und Ergebnisse der Naturwissenschaft zu ignorieren.

Der Uberblick über die Scientia meteororum des 17. Jahrhunderts, deren Geschichte freilich erst noch zu schreiben wäre, muß damit sein Bewenden haben, und es stellt sich nun die Frage, wie sich das Reinzersche Werk, um das es uns hier geht, in diese Tradition einfügt.

\subsection{Die Meteorologia philosophico-politica in der gelebrten Tradition}

Zunächst ist festzuhalten, daß Franz Reinzer natürlich kein Fachmeteorologe, ja noch nicht einmal Naturwissenschaftler im modernen, berufs- und ausbildungsbezogenen Sinne war, und es hieße, den Charakter von Wissenschaft in der frühen Neuzeit verkennen, wollte man ihn und sein Werk an einem solchen Anspruch messen. Historisches Interesse gewinnt die Meteorologia philosopbico-politica für uns von allem deshalb, weil sie in exemplarischer Weise vor Augen führt, wie die 
frühneuzeitliche Wissenschaft von den meteora in die Unterrichtspraxis und das Leben ihrer Zeit hineinwirkte.

Reinzer hat aus seiner mangelnden Originalität und Unsicherheit in fachwissenschaftlicher Hinsicht keinen Hehl gemacht und den geneigten Leser eigens ersucht, sein « aus den bewehrtesten Scribenten auf gegenwärtige neue Manier zusammengesetztes Wercklein » nicht mit dem «Läster =Zahn » der Kritik zu zerfetzen. ${ }^{86}$ Gleichwohl überrascht seine Belesenheit in alten und neueren Autoren, auch wenn so mancher gelehrte Verweis in bewährter Manier aus den gern und häufig zitierten Werken seines Ordensbruders Athanasius Kircher, den er gelegentlich « unseren Kircherus » nennt, übernommen sein mag. ${ }^{87}$ Hier sind es vor allem Kirchers Magnes sive de arte magnetica (Rom 1643), Ars magna lucis et umbrae (Rom 1646), Iter exstaticum coeleste (Rom 1656) und der Mundus subterraneus (Rom 1665), kompendiöse Kompilationen, die in zahlreichen Auflagen verbreitet waren und unerschöpfliches Material lieferten. Aber auch auf private Mitteilungen aus dem Museum Kircherianum des großen Universalgelehrten kann Reinzer sich hier und da berufen, ${ }^{88}$ als deren Übermittler am ehesten dessen Schüler, der Würzburger Jesuitenprofessor Caspar Schott infrage kommt, dessen Magia universalis (Würzburg 1657-1659) und Pbysica curiosa (Würzburg 1662) Reinzer ebenso häufig konsultierte. Die älteren Kompendien sind mit Girolamo Cardanos De rerum varietate (Basel 1557) und De subtilitate (Nürnberg 1550) und Julius Caesar Scaligers Gegenschrift Exotericarum exercitationum liber XV. (Paris 1557) vertreten; dazu natürlich die speziell meteorologischen Werke, angefangen von Aristoteles' Meteorologica und De generatione et corruptione, Senecas Naturales Quaestiones oder dem zweiten, kosmologisch-meteorologischen Buch von Plinus' Naturalis bistoria, bis hin zu Libert Froidmonts Meteorologicorum libri IV (Löwen 1627) und JeanBaptiste Duhamels De meteoris et fossilibus libri II (Paris 1660). Für einzelwissenschaftliche Fragen sind Georg Agricolas De ortu et causis subterraneorum (Basel 1546), Olaus Magnus' Historia de gentibus

86 Meteorologia (1712), fol. )(2v. Des leichteren Verständnisses zuliebe ist im folgenden meist nur nach der deutschen Ubersetzung zitiert, obgleich damit, was die naturwissenschaftliche Terminologie angeht, zusätzliche Probleme auftauchen. Im Zweifelsfall sind deshalb die lateinischen Termini zusätzlich aufgeführt.

87 Wo im folgenden Erscheinungsorte und -daten angegeben sind, dient dies nur zur historischen Einordnung der Quellen und nicht zur Kennzeichnung der von Reinzer benutzten Ausgaben. Viele dieser Werke sind mehrfach aufgelegt und gelegentlich sogar in die Landessprachen übersetzt worden.

$88 \mathrm{Vgl}$. etwa Meteorologia (1712), S. 202, 211. 
septentrionalibus (Rom 1555) und William Gilberts De magnete (London 1600) herangezogen. Aber auch Kepler, Mersenne und Descartes fehlen nicht in der Reihe der von Reinzer zitierten Autoren und Autoritäten. $\mathrm{Da}$ er die Literatur seiner Zeit nicht zur Kenntnis genommen habe, wird man ihm nicht vorwerfen können. Rezente Ergebnisse sind sogar aus den seit 1670 erscheinenden Miscellanea curiosa medicopbysica, den Ephemeriden der Schweinfurter gelehrten Gesellschaft übernommen, die seit 1687 den Titel einer Kaiserlich-Leopoldinischen Akademie der Naturforscher führte.

Reinzer verwendet nun diese Literatur in einer durchaus charakteristischen Weise. Anders als Froidmont, Fabri oder Duhamel, die der gelehrten Kontroverse breiten Raum einräumten und dabei meist auch die gegnerische Ansicht ausführlich zu Wort kommen ließen, ist Reinzer eher auf den Kompromiß und die Harmonisierung widerstreitender Meinungen bedacht, wobei natürlich auch die didaktische Bestimmung des Werkes eine Rolle gepielt haben wird. Sein Eklektizismus bevorzugt das Faktische. Säuberlich in Dissertationes, Quaestiones und Conclusiones, diese wiederum in Einwände und Antworten unterteilt, herrscht die lehrhaft-einprägsame Sentenz vor. Theoretischen Spekulationen ist Reinzer abhold, weil es dabei meist um eine Sache gehe, "die bißhero kaum durch Menschlichen Verstand hat können ergründet werden: dann man findet dißfalls fast so viel Meinungen als Köpffe ».99

Umfang und Gegenstandsbereich von Reinzers Meteorologie sind traditionell definiert und entsprechen im großen und ganzen denen der Aristotelischen Meteorologica, wie dies im Grunde ja für fast alle Werke dieses Genres zutrifft.

Die erste Abhandlung gilt wie üblich den meteorologischen Körpern im allgemeinen, ihrer Materie und bewirkenden Ursachen, dem kosmologischen Ort der meteorologischen Phänomene, der Unterscheidung von vollständig und unvollständig Gemischtem und - hier scheint auf einmal der Theologe durch - der Frage, ob sich die Himmelserscheinungen auf ausschließlich natürliche Ursachen zurückführen ließen oder daneben noch andere causae finales besäßen. Kosmologie und Anatbymiasis-Lehre von Aristoteles liegen der Definition des meteorum zugrunde. Reinzer nennt es « ein vermischtes, unvollkommenes, in den obern Welt $=$ Theilen entsprungenes Wesen ${ }^{90}$ wozu im weiteren Sinne auch die effluvialen Erscheinungen der unteren Luftschichten und

89 Meteorologia (1712), S. 391.

90 Meteorologia (1712), S. 1. 
die « vollkommen vermischten » stofflichen Ausscheidungen des Meeres und der Erdrinde zählen. Entsprechend der Lehre von xarvòs und à ruis sind Erde und Wasser ihre materia remota, ihre materia proxima hingegen die "warme und feuchte Aushauchung" des Wassers bzw. die « warme und druckne Aushauchung » erdiger Substanzen. Damit werden neuplatonisch-hermetische Vorstellungen, wonach astrale Effluvien in der Meteorologie eine Rolle spielten und die hier dem Paracelsus, « der Alchemisten Heerführer » zugeschrieben werden, als « seltsame Träume und Einfälle » entschieden zurückgewiesen. ${ }^{91}$ Eine sympathetische actio in distans der Himmelskörper, z.B. die «wasserziehende " Kraft des Mondes, ist ausdrücklich verneint. Bewirkende Ursache aller atmosphärischen Erscheinungen sei vielmehr die Wärme, die sowohl von der Sonne, als auch von unterirdischen Feuern herrühren könne. Große Aufmerksamkeit wird deshalb dem merkwürdigsten Teil der aristotelischen Meteorologie und Wärmelehre, der Lehre von der antiperistasis zuteil, die als Erklärung immer dann herhalten muß, wenn eine Einwirkung von Kälte oder Wärme für den beobachteten Effekt zwar theoretisch erforderlich, physikalisch jedoch nicht manifest ist. $\mathrm{Zu}$ dieser antiperistasis, die im Anschluß an Aristoteles (Meteor. 348b2 und $382 \mathrm{~b} 22$ ) in der gesamten naturphilosophischen Literatur des 17. Jahrhunderts eine enorme Rolle spielt, meint Reinzer, daß Kälte bzw. Wärme

bloß deßwegen sich vermehren/ weilen sie von einer widrigen Würckung/ die mächtig ist/ sie zu vernichten/ umbgeben wird [...] dahero/ daß sie von einer widrigen Würckung gleichsam belagert und bloquiret werden. Und dieses/ da die rings umbstehende Würckung die widrige Eigenschafft ergrössert und vermehret/ pflegen die Philosophi Antiperistain oder eine Umbstellung zu nennen. ${ }^{92}$

Mit dieser paradoxen Erklärung wie es scheint nicht ganz zufrieden, liefert Reinzer selbst eine korpuskularmechanische Deutung nach, derzufolge die dünnen und spirituösen Teilchen eines warmen Körpers vor der umgebenden Kälte ins Innere des Körpers fliehen und dort folglich die Wärme vermehren, während umgekehrt umgebende Wärme die Poren eines Körpers erweitert, so daß alle wärmeren und leichteren Teile austreten können, wodurch die kälteren nach innen gedrückt werden und dort die Kälte vermehren. Eine Illustration dieses Vorganges

91 Meteorologia (1712), S. 2.

92 Meteorologia (1712), S. 8. 
liefert seine der Cartesischen Theorie verwandte Deutung des Zustandekommens von Hagel. ${ }^{93}$ Für Reinzer

besteht seine entfernte Materi in einer Ausdünstung/ die vermittelst würckender grosser Hitze in die Höhe gestiegen/ und zu einer etwas festen und warmen Wolcke sich verdichtet hat: seine nahe Materi aber ist der Platz= Regen/ in den die Wolcke auffgelöset wird; und seine nahe würckende Ursache ist gleichfalls die Wärme der umbstehenden Lufft/ welche Krafft der Antiperistasi oder Gegenumbstellung das Wasser erkältet/ und alle Wärme aus demselben austreibt. ${ }^{94}$

Deutlich zeigt sich der Unterschied zur 'moderneren' Richtung der zeitgenössischen Naturwissenschaft, wo es darum geht, das Verhältnis von mechanischer Ursache und Finalursache zu bestimmen: In der fünften Frage des Einleitungskapitels untersucht Reinzer, « $\mathrm{Ob}$ alle Meteoren aus natürlichen Ursachen entspringen? und ob sie etwas vorbedeuten können; wie auch was ihre End=Ursache? $\gg .{ }^{95}$ Zunächst stellt er fest, daß grundsätzlich nur natürliche Ursachen anzunehmen seien, muß aber aus theologischer Rücksicht auch die gelegentliche Mitwirkung von Engeln und Dämonen gelten lassen, wofür er nicht nur Martin Delrios berüchtigte Disquisitiones magicae (Löwen 1599), sondern auch Caspar Schotts Pbysica curiosa ${ }^{96}$ als Beleg anführt. Unentschieden ist Reinzer auch hinsichtlich der Frage, ob atmosphärische Erscheinungen kommende Ereignisse vorausbedeuten können. Daß hier Zusammenhänge bestehen, scheint die Erfahrung nahezulegen, doch neigt er zur rationalen Deutung, daß gleiche Ursachen auch gleiche Wirkungen hervorbringen, weshalb feurige Ausdünstungen sowohl feurige Luftzeichen als auch entsprechende Wirkungen auf den Körper und den Geist des Menschen zur Folge haben. Als Vorboten kommenden Unheils will er dergleichen Erscheinungen allenfalls insofern gelten lassen, als

solcherley Wunder =Zeichen nichts destominder aus natürlichen Ursachen/ die von der Göttlichen Weißheit vorbestimmt und bereitet werden/ auf daß sie zu gewisser Zeit zu ein = oder anderer Würckung/ als etwa zu Entzündung und Anfeurung der Cometen/ ihren Beytrag thun können/ entspringen. ${ }^{97}$

$93 \mathrm{Vgl}$. auch Middleton (wie Anm. 66), S. 194-196.

94 Meteorologia (1712), S. 211.

95 Meteorologia (1712), S. 21-22.

96 C. Schotr, Physica curiosa, Würzburg 1662, Bd. I, Kap. 34.

97 Meteorologia (1712), S. 22. 
Erst wo es um die Endursache der Naturerscheinungen insgesamt geht, zeigt sich das teleologische Naturverständnis Reinzers, das bei der Erklärung der Einzelphänomene kaum in Erscheinung tritt:

Weilen in der Natur alle Dinge zu einem gewissen Zweck und Ende abzielen, so ist der Meteoren Grund=Ursache auch entweder Physicalisch oder Natürlich oder Theologisch. Jene oder die natürliche End=Ursache bestehet darinn/ daß die gantze Welt recht und wohl regieret/ die Elementen miteinander nutzbarliche vermenget/ die Lufft gereiniget/ und die Erde fruchtbar gemacht werde [...] so daß solcher Gestalten alle Meteoren zum gemeinen besten aus einer natürlichen End=Ursache ausschlagen und gedeyen. Die andere End=Ursache aber ist/ wie gemeldt/ Theologisch; und bestehet in der Erkänntnus, Liebe und Ehre Gottes/ wie auch in Erschreckung der Gottlosen.98

Die zweite Dissertation der Meteorologia philosophico-politica behandelt die feurigen Meteore, deren physikalische Endursache für Reinzer in der Verbrennung irdischer Ausdünstungen bestand. Hier begegnen uns nun allerhand zweifelhafte Lichterscheinungen der Atmosphäre, Sternschnuppen und Nordlichter, Elms- und St. Helens-Feuer, die «Ziegen » und « Fackeln » der Aristotelischen Meteorologica, die auch alle früheren Interpreten beschäftigt hatten, und was dergleichen mehr ist. Reinzers Darstellung ist hier betont nüchtern, ja skeptisch. Die abergläubische Furcht vor außergewöhnlichen Himmelserscheinungen war ja weit verbreitet. Volkstümliche Wetterregeln, Dämonenfurcht und frommer Wetterzauber führten zu den wunderlichsten Ansichten und Verhaltensweisen. Wie sollte dies im agrarisch-ländlichen Oberösterreich anders gewesen sein? Es wird seine Gründe gehabt haben, daß das Linzer Jesuitenkolleg, an dem Reinzer lehrte, von Anfang an den Kampf gegen den Volksaberglauben als eine seiner wichtigsten erzieherischen Aufgaben angesehen hatte. 99 Reinzers Meteorologie fügt sich durchaus in dieses ' aufklärerische' Programm. Dabei sind es die Argumente der aristotelischen Kosmologie und die abstrakte Rationalität der scholastischen Naturphilosophie, mit denen er dem meteorologischen Aberglauben zu Leibe rückt. Bisweilen treten Empirie und eigene Beobachtung hinzu. Aber gerade die Empirie war ja stets auch mit widersprechenden Beobachtungen und sogar haarsträubenden Tatsachen-

98 Ebenda, S. 22.

99 Vgl. H. Commenda, Die Litterae Annuae des Linzer Jesuitenkollegs als Quelle der Volkskunde, « Historisches Jahrbuch der Stadt Linz 1961 », 1962, S. 119-138, hier bes. S. $129-131$. 
berichten aus der Feder von Autoren konfrontiert, die ansonsten als zuverlässige und kritische Gewährsleute galten. In solchen Fällen entschied sich Reinzer meist zugunsten der aristotelischen Ansicht. So urteilt er etwa über die «fliegenden Drachen » gewisser Autoren, « allein/ wir verwerffen diese wahnwitzige Grillen und halten es mit dem Aristotele », ${ }^{100}$ denn im Grunde handele es sich immer wieder bloß um komprimierte Ausdünstungen, die sich durch antiperistasis oder Reibungswärme entzünden. Es sei daher Unfug, derartigen Erscheinungen abergläubische Bedeutungen beizumessen, zumal viele von ihnen sich leicht nachahmen ließen, wozu Reinzer einen mit alkoholischer Kampher-Lösung getränkten und mit Schießpulver bestreuten Lederriemen empfiehlt, den man in Brand stecken und von einem erhöhten Standort aus in die Luft werfen solle.

Die dritte Dissertation geht um Blitz und Donner, die ganz konventionell erklärt werden: Aus einer umschließenden Wolkenschicht breche zunächst mit lautem Krachen die darin angesammelte und komprimierte schweflig-salpetrige Ausdünstung hervor, die sich sodann durch Reibung der Wolken aneinander oder Antiperistasis-Wirkung der kalten Umgebungsluft entzünde. Daß die Wahrnehmung beider Phänomene im umgekehrter Reihenfolge geschieht, erkläre sich aus der momentanen Ausbreitung der Lichtspecies und der geringen Geschwindigkeit des Schalls.

Bei der Behandlung der Kometen in der vierten Dissertation zeigt Reinzer sich durchaus vertraut mit der Astronomie seiner Zeit. Daß echte Kometen Bahnen weit jenseits des Mondes beschreiben, steht für ihn außer Frage. Die Tatsache, daß Parallaxen von Kometen nicht zu beobachten waren und ihre tägliche Bewegung der der Fixsterne folgt, sind für Reinzer Beweise genug. Tycho Brahe und Johannes Kepler werden aufgeboten, um in dieser Hinsicht den alten Aristoteles zu widerlegen und mit ihm all diejenigen,

die da die gantze Nacht in ihrer sanfften Ruhe und Schlaff ligen/ und wann sie vielleicht den Aristotelem einmahl durchgeblättert/ nur darum/ weilen selbiger solchem widerspricht/ es für Irrthum halten und ausschreyen. Allein/ wo die Wahrheit klar und offenbahr am Tage liget/ und das Widerspiel zeiget/ da hat man sich keines Weges an das Ansehen oder Meynung besagten Philosophi zukehren; welcher jedoch dißfalls auch gar wohl kan entschuldigt werden/ weilen man zu seiner Zeit noch nicht so viel neue Sterne entdeckt/ oder die Paralaxes untersucht gehabt. ${ }^{101}$

100 Meteorologia (1712), S. 40.

101 Meteorologia (1712), S. 83. 
Wenn die Kometen aber der Himmelsregion angehören, so kann die Frage nach ihrer Materie nicht aristotelisch beantwortet werden. Unter Berufung auf Willebrord Snel, Christoph Rothmann, Johann Hevelius und René Descartes meint Reinzer deshalb, sie entstünden aus von der Sonne oder den Planeten « ausfliessender himmlischer Materi oder Dampff », ${ }^{102}$ die von der Kraft der Gestirne zusammengetrieben und entzündet würde, so daß sie hinsichtlich Entstehung und stofflicher Natur am ehesten den Fackeln und Protuberanzen der Sonne zu vergleichen seien. Was ihren prognostischen Wert für das menschliche Schicksal angeht, so ist Reinzer sicher, dieser sei « auf keinem festen Beweiß/ sondern bloß auf einem eitelen Fürwitz gegründet $\gg{ }^{103}$

Die fünfte Dissertation der Meteorologia philosophico-politica behandelt die scheinbaren Meteore wie Wolken- und Himmelsfärbungen, Haloerscheinungen und optische Phänomene. Zu Recht wird die Milchstraße als Ansammlung von Fixsternen und deshalb nicht zu den Meteoren gehörig erkannt und denen, die immer noch zweifelten, ein Blick durch das Fernrohr empfohlen. Seltsam konservativ mutet dageben die Erklärung des Regenbogens an, der gut aristotelisch als Reflexion des Sonnenlichts an einer hohlen Wolke vorgestellt wird, in deren Tröpfchen sich die Sonne spiegele, wobei die Farben aus der Mischung von Licht und Trübe des Medium zustandekommen sollen. Weshalb Reinzer hier der in der von ihm konsultierten Literatur doch verfügbaren modernen Brechungstheorie nicht hat folgen wollen, ist nicht recht ersichtlich.

In der sechsten Dissertation geht es um die Luftmeteore, d.h. besonders die Winde. Kontrovers war hier vor allem die in der meteorologischen Literatur des 16. und 17. Jahrhunderts mit erbittertem Eifer erörterte Frage, ob Wind "Bewegung in der Luft » oder « Luft in Bewegung » sei. Was uns wie ein müßiger Streit um Worte erscheint, berührt in der Tat einen Fundamentalsatz der aristotelischen Kosmologie. Denn Luft befand sich danach ja doch an ihrem natürlichen Ort und hätte eines äußeren Bewegers bedurft, um in Bewegung zu geraten, die aber sogleich wieder zur Ruhe gekommen wäre. Wind sollte nach peripatetischer Lehre deshalb ein tertium quid sein, das sich in der Luft, der hierbei nur die Funktion eines Mediums zukommt, vollzieht. Dafür aber kamen wieder nur die anatbymiaseis der Erde in Betracht. Wie so oft entscheidet sich Reinzer auch hinsichtlich der Materie der Winde für ein sowohl-als-auch: Neben der Aristotelischen Annahme einer exbalatio calica et sicca, der nach seiner Meinung auch feuchte Dünste beigemischt

102 Meteorologia (1712), S. 87.

103 Meteorologia (1712), S. 106. 
sein können, neigt er dazu (probabile mihi est), auch eine reine Bewegung der Luft selbst zuzulassen, für deren Bewegungsursache er verschiedene Beispiele aufzählt.

Die siebente Dissertation gilt den Hydrometeoren, der Bildung von Wolken und Nebel, der Erklärung von Regen und Schnee, wobei Reinzer weitgehend Cartesischen Ansichten folgt. Unübersehbar auch hier die teleologische Argumentationsrichtung, wenn es etwa von der natürlichen Endursache des Schnees heißt, er befeuchte und befruchte die Erde, wärme das Saatgut, indem er dessen Poren, aus denen Wärme entfliehen kann, verschließt, mache die Hände "so man sie darmit waschet, hart und fett » und wirke der Fäulnis und Verwesung entgegen. ${ }^{104}$ Natürlich kann in einem Kapitel über die Hydrometeore auch die alte Streitfrage, ob Honig eine Art Tau oder ein Saft der Blumen sei, nicht fehlen. Reinzer beantwortet sie wie so oft mit einem Kompromiß, wonach die Materie des Honigs « theils in einem erdischen Dampff und Ausdünstung/ so sich zu einem Thau verdicket; theils in den reinesten Ausdünstungen der Blumen/ wovon fürnemlich die Süssigkeit herkommet » bestehe. ${ }^{105}$ Aber auch die üblichen Beispiele aus der biblischen Naturgeschichte gehören in diesen Zusammenhang: der Honig, von dem sich Johannes der Täufer nährte, und das Manna, das Gott dem Volk Israel in der Wüste von Himmel regnen ließ. Bedenkt man, daß derartige «Wunderregen » selbst noch im Kontext der seriösesten naturwissenschaftlichen Meteorologie des frühen 19. Jahrhunderts als empirische Tatsachen diskutiert wurden, ist ihre zurückhaltend kritische Darstellung bei Reinzer durchaus bemerkenswert.

Interessant ist die achte Dissertation, die von den Hydrometeoren der Erdoberfläche, besonders aber vom Meer handelt, dessen Salzgehalt teils mit «verbrannten Ausdünstungen » der Erde, überwiegend aber damit erklärt wird, «daß Gott/ als Urheber der Natur/ in Anfang der erschaffenen Welt [...] allen Meer $=$ Wassern ein flüssiges Saltz zur Erhaltung der Fisch und der Fäulung des Wassers darmit zubegegnen/ mit untergemenget habe ». ${ }^{106}$ Das naturwissenschaftliche Kernproblem der Meereskunde blieb freilich die Erklärung von Ebbe und Flut. Bekanntlich hatte auch Galilei mit seiner eigenen Gezeitentheorie, die die Bewegung der Erde beweisen sollte, keine allzu glückliche Hand. Reinzer wählt zunächst eine rein phänomenologische Beschreibung, um dann, angefangen bei Aristoteles, die unterschiedlichsten Theorien vorzustellen

104 Meteorologia (1712), S. 206.

105 Meteorologia (1712), S. 221.

106 Meteorologia (1712), S. 236-237. 
und sämtlich zu widerlegen. Besonders scharf geht er mit der aus der hermetischen Tradition herrührenden Ansicht Keplers ins Gericht, « die Erde seye ein grosses Thier/ so mittelst der ungeheuren $\mathrm{Bla} ß=\mathrm{Bälgen}$ der Lungen das Meer $=$ Wasser zu gewisser Zeit in das Ingeweid einlasse/ und wieder heraus blase ». ${ }^{107}$ Der Versuch, die Gezeiten mit der Erdbewegung in Zusammenhang zu bringen - von Reinzer nicht Galilei, sondern Andrea Cesalpino ${ }^{108}$ und einem Heinrich von Utrecht zugeschrieben - erscheint ihm physikalisch so abwegig wie «die Meinung von der Engel Beyhülff nicht philosophisch: denn wo man von einer natürlichen Würckung redet/ da muß der Philosophus oder Weltweise eine Ursach solcher natürlichen Würckung anzeigen $»{ }^{109}$ Eine solche freilich weiß er selbst auch nicht anzubieten und glaubt deshalb, daß er « hier statt der Antwort nichts anders zu thun/ als mit dem Prediger Salomo auszuruffen habe: verwunderlich seynd die Wercke deß Höchsten; sie seynd herrlich und verborgen $\gg .{ }^{110}$

Die neunte Dissertation handelt von den Quellen und Flüssen, Thermen und Mineralwässern sowie der Umwandlung von Wasser in Eis; die zehnte vom Erdbeben, das zu den meteora zählt, weil als Ursache aus der Erde hervorbrechende Dünste oder unterirdische Feuersbrünste gelten; die elfte dann von den Bergen, Höhlen, Klüften und den unterirdischen Feuern, die, wie Reinzer selbst zugesteht, nicht eigentlich zu den meteora rechnen, doch wegen ihrer sachlichen Zugehörigkeit hier abgehandelt werden. Dabei verläßt er sich im wesentlichen auf Georg Agricola.

Von größtem inhaltlichen Interesse ist schließlich die zwölfte und letzte Dissertaton der Meteorologia philosophico-politica, die den « Fossilien », d.h. Mineralien, und den Metallen gilt. Wenn auch dieses Gebiet nicht eigentlich zur Meteorologie gehört, so folgt Reinzer damit doch einer alten Tradition, die sich auf die inhaltliche Verwandtschaft des vierten Buchs der Aristotelischen Meteorologica mit De generatione et corruptione berufen kann. Auch Jean-Baptiste Duhamel, einer seiner maßgeblichen Gewährsleute, hatte in De meteoris et fossilibus (Paris 1660) Mineralogie und Meteorologie in einem Band vereint. Darüberhinaus waren beide Wissensgebiete durch einen gemeinsamen theoreti-

107 Ebenda, S. 254; vgl. J. KePler, Harmonice mundi, Linz 1619, IV, 7, in ders., Gesammelte Werke, Bd. VI, hrsg. von M. CASPAR, München 1940, S. 270.

${ }_{108} \mathrm{Zu}$ den kaum untersuchten kosmologischen Ansichten dieses bedeutenden Mediziners und Botanikers siehe E. GRANT, In Defense of the Earth's Centrality and Immobility:

- Scbolastic Reaction to Copernicanism in the Seventeenth Century ("Transactions of the American Philosophical Society », 74, 4), Philadelphia 1984, S. 6-9.

109 Meteorologia (1712), S. 254.

110 Ebenda, S. 255; wohl kein Zitat, vgl. aber Eccl. 11, 5. 
schen Rahmen verbunden, weil Mineralien, Metalle und verschiedene mineralische Konkretionen als feuchte Ausdünstungen der Erde galten, die die Wärme des Erdinneren an die Erdoberfläche treibe, wo sie durch die dort herrschende Kälte kondensieren und sich an Steinen abscheiden. ${ }^{11}$ Was das mineralogisch-metallurgische Fachwissen angeht, so folgt Reinzer in diesem Teil neben Duhamel vor allem Plinius' Naturalis bistoria, Pietro Andrea Matthiolis Commentarii in libros Dioscoridis de medica materia (Venedig 1554), Georg Agricolas De re metallica (Basel 1556), De natura fossilium und De ortu et causis subterraneorum (Basel 1546) sowie Anselm Boetius de Boodts Gemmarum et lapidum historia (Hanau 1609).

Besondere wissenschaftsgeschichtliche Beachtung verdienen die Abschnitte über den Bernstein und den Magneten, weil beide Objekte zu Ausgangspunkten der neuzeitlichen experimentellen Physik werden sollten. Denn im Magnetismus und in der statischen Elektrizität lagen neuartige Phänomene vor, bei deren Deutung die antiken Autoren vollkommen versagten. Zudem waren es Beispiele einer unstreitigen actio in distans, welche die Grundfesten der aristotelischen Physik erschütterten. William Gilbert war es gewesen, der als erster klar zwischen magnetischer Anziehung und der Anziehung durch Reibungselektrizität unterscheiden konnte. Sein De magnete magneticisque corporibus (London 1600) markiert den Beginn experimentalphysikalischer Forschung im modernen Sinne.

Zwei Fragen sind es, die Reinzer am Bernstein, den er « Agtstein » nennt, besonders interessieren: seine stoffliche Beschaffenheit und die Natur der beim Reiben auftretenden Anziehungskraft. Letztere versucht er stofflich zu deuten, da ihn weder die korpuskulare Theorie der elektrischen Anziehung überzeugt, wie sie Descartes in den Principia ${ }^{112}$ vorgestellt hatte, noch die Annahme einer «besonderen Sympathi oder natürlichen Zuneigung », die nach seiner Ansicht eine gemeinsame stoffliche Natur von Anziehendem und Angezogenem zur Voraussetzung hätte. Reinzers Theorie der elektrischen Attraktion beruht auf der Annahme spezifischer Ausdünstungen, die vom elektrisierten Körper ausgehen und die anziehende Wirkung stofflich vermitteln. Sie fügt sich damit zwanglos in den Rahmen der Anathymiasis-Lehre und zeigt große Verwandtschaft zur Gilbertschen Auffassung vom elektrischen Effluvium ${ }^{113}$ in der Form,

111 Vgl. Meteorologia (1712), S. 352.

112 R. Descartes, Principia philosophiae [1644], IV, 185, in Oeuvres de Descartes, hrsg. von C. AdaM und P. TANNERY, Bd. VIII, Paris 1905, S. 312-313.

$113 \mathrm{Vgl}$. dazu G. FreudentHal, Die elektrische Anziebung im 17. Jabrbundert zwischen korpuskularer und alchemischer Deutung, in Die Alchemie in der europäischen Kultur- und 
wie sie von Kircher, Schott und dessen Schüler Francesco Lana weiterentwickelt worden war. ${ }^{114}$ Danach sei der Grund der Anziehung in einer feuchten und zähen Ausdünstung zu sehen, an der leichte Teilchen wie Strohhalme oder Papierschnitzel kleben blieben. Als Beweis dieser Ansicht führt Reinzer an, daß zur Erzeugung der elektrischen Eigenschaft Reibung, mithin Wärme erforderlich sei, die aber keine andere Wirkung habe, als eben die, die Poren des Bernsteins zu öffnen, so daß die eingeschlossene feuchte Materie austreten könne, wie der dabei auftretende Geruch belege. Die Rolle der Poren und die Beteiligung eines stofflichen Effluviums folge auch aus der Beobachtung, daß mechanische Erschütterungen, feuchte Luft und die Berührung mit nassen oder fettigen Händen den Effekt aufheben, da auf diese Weise die Poren der Oberfläche verstopft und die eingeschlossene Feuchtigkeit am Austreten gehindert würden. Auf diese Weise war zugleich die Tatsache erklärt, $\mathrm{da} ß$ angezogene Staubteilchen oder Strohhalme, sobald sie den elektrisierten Körper berührt hatten, von diesem wieder abgestoßen wurden: für Reinzer ein « offenbahres Zeichen [...] daß die Ausflüsse hervorbrechen/ und wie der Wind das Pulver zerstäuben $» .{ }^{115}$ - All dies mag uns unbeholfen und gewaltsam erscheinen, doch entsprechen die in der Meteorologia philosopbico-politica vertretenen Auffassungen durchaus dem Stand der Elektrizitätslehre bis zum Jahre 1700.

Was Reinzers Kenntnisse des Magnetismus betrifft, so dürften sich diese im wesentlichen von Athanasius Kirchers Magnes sive de arte magnetica (Rom 1643) herleiten. Theorie und Gebrauch des Kompasses sind ihm vertraut, er erwähnt Deklination und Inklination, kennt den Erdmagnetismus und weist darauf hin, daß die Magnetnadel sich nach den Erd-, nicht den Himmelspolen ausrichte. Wir finden die Armierung des Magnetsteins mit Eisen zur Verstärkung seiner Wirkung und den Nachweis der Feldlinien mit Eisenfeilspänen. Doch auch Irrtümer übernimmt Reinzer aus der in dieser Hinsicht meist recht kritiklosen Literatur, wie etwa die bereits in der Antike vertretene und seither bedenkenlos kolportierte Ansicht, Diamant ${ }^{116}$ oder Knoblauch ${ }^{117}$ höben die Wir-

Wissenschaftsgeschichte der Neuzeit, hrsg. von CH. MeINEL ( Wolfenbütteler Forschungen », 32), Wiesbaden 1986, S. 315-326.

114 Bes. in F. Lana TerzI, Magisterium naturae et artis, Bd. III, Brescia 1692, S. 287-312. Auch Lana war Jesuit wie Schott und Kircher.

115 Meteorologia (1712), S. 368.

116 So Plinius, Naturalis historia 37, 15.

117 So bereits Proklos, von den Humanisten dann mit einer Textkorruptele (alio statt allio in Plinius, Naturalis bistoria 20,1) gerechtfertigt; siehe auch H. BALMER, Beiträge zur Geschichte der Erkenntnis des Erdmagnetismus ( « Veröffentlichungen der Schweizerischen Gesellschaft für Geschichte der Medizin und der Naturwissenschaften », 20), Aarau 1965, S. 44-45. 
kung des Magneten auf. Daß bereits Giovanni Battista della Porta in seiner Magia naturalis (Neapel 1589) diese angeblich antipathetischen Wirkungen experimentell widerlegt hatte, scheint Reinzer unbekannt. Freilich war gerade bei einem Gegenstand wie dem Magneten Vorsicht geboten, um nicht in die Nähe der theologisch wie naturphilosophisch bedenklichen neuplatonisch-hermetischen Sympathielehre zu geraten; war doch gerade der Magnet immer das Paradebeispiel für derartige Fernwirkungen gewesen. Vor Autoren wie della Porta galt es daher auf der Hut zu sein. Reinzer legt großen Wert darauf, die Anziehung des Magnetsteins als eine rein akzidentielle Wirkung zu betrachten, deren Ursache «bißhero kaum durch Menschlichen Verstand hat können ergründet werden ${ }^{118}$ Er strengt sich an, auch hier eine - in ihrem Eklektizismus nicht sonderlich überzeugende - stofflich-materielle Erklärung anzubieten, bei der die "Sympathi oder Wesens=Gleichheit » von Eisen und Magneteisenstein einen gewissermaßen vegetativen $\mathrm{Zu}$ sammenhang von Ursache und Wirkung herstellt. Der Magnet habe demnach ein "Leben », und das Eisen sei seine natürliche Nahrung. Hebe man einen Magneten längere Zeit in Eisenfeilspänen auf, so könne man sehen, daß dieser "einen Theil darvon verzehret habe », was Reinzer jedoch keinesfalls vitalistisch, sondern als Streben der Elemente $\mathrm{zu}$ ihren natürlichen Örtern verstanden wissen will. ${ }^{119}$ Die aristotelische Kosmologie und Materielehre scheint eben auch hier wieder durch.

\section{Meteorologia emblematica}

« Nulla res est sub sole », beteuerte 1687 Bohuslaus Balbinus, « quae materiam emblemati dare non possit $\gg .^{120}$ In der Tat hatten die zurückliegenden 150 Jahre, ausgehend von der Überzeugung, daß die Welt in all ihren Erscheinungen von heimlichen Verweisungen, verborgenen Bedeutungen und entdeckungsfähigen Sinnbezügen erfüllt sei, Bilderwelten und Weltenbilder hervorgebracht, die ihresgleichen suchen. ${ }^{121}$ Form- und namengebend wurde hier der Emblematum liber des Mailän-

118 Meteorologia (1712), S. 391.

119 Meteorologia (1712), S. 391. S. 234.

120 B. Balbinus, Verisimilia bumaniorum disciplinarum, 2. Aufl., Augsburg 1710,

121 Zur Emblematik vgl. vor allem Emblemata: Handbuch zur Sinnbildkunst des XVI. und XVII. Jabrhunderts, hrsg. von A. HeNKEL und A. SCHÖNE, Stuttgart 1967; ferner P. M. Daly, Emblem Theory: Recent German Contributions to the Characterization of the Emblem Genre («Wolfenbütteler Forschungen», 9), Nendeln 1979. 
der Juristen Andrea Alciati, dessen Editio princeps 1531 in Augsburg erschienen war. Charakteristisch für das Emblem ist die Doppelfunktion von Repräsentation und Interpretation, Darstellung und Deutung, Abbildung und Auslegung. In seiner klassischen Form besitzt es dreiteiligen Aufbau: $\mathrm{Da}$ ist zunächst als kleiner Holzschnitt oder Kupferstich die Pictura, ein Deutebild von potentieller Faktizität, das als Sinnbild vorgefundene Realien aus der bistoria naturalis et artificialis aufnimmt oder als Allegorie eigene Wirklichkeiten konstituiert. Der Pictura zugeordnet und bisweilen in ihr Bildfeld integriert dann die Inscriptio oder das Motto, oft sentenzenhaft und aenigmatisch Deutung herausfordernd. Schließlich die Subscriptio in Epigramm oder Prosatext, die die Auslegung des Dargestellten vorträgt und die res picta zur res significans werden läßt mit festem Sinnbezug zum Menschenleben.

$\mathrm{Daß}$ die Vorgänge der Atmosphäre schon immer in besonderem $\mathrm{Maße}$ ursächliche Erklärung und sinnhafte Deutung herausforderten, bedarf kaum der Erläuterung, zumal wenn es um Zeiten geht, in denen die Menschen den Segnungen und Unbilden der Witterung sehr viel unmittelbarer ausgesetzt waren als wir es uns heute, künstlich vor Wind und Regen, Hitze und Kälte beschirmt, noch vorstellen mögen. Die Wirkung atmosphärischer Vorgänge, den Einfluß von Sonne und Mond auf belebte und unbelebte Natur beobachten hieß aber auch, nach Entsprechungen und Wirkungszusammenhängen, ja nach dem Zeichen- und Vorzeichencharakter der meteora zu fragen. Die gelehrten und populären Prognostiken, die nach jedem Auftauchen eines Kometen, jeder besonders merkwürdigen Haloerscheinung gedruckt wurden, sprechen hier eine unmißverständliche Sprache. ${ }^{12}$ Malerei und Dichtung der Zeit belegen eine intensive Auseinandersetzung mit den atmosphärischen Phänomenen und ihren Deutungen einschließlich der meteorologisch-naturwissenschaftlichen Theorien. ${ }^{123}$ Selbst Descartes, der sonst dergleichen weit von sich gewiesen hätte, leitete die Météores von 1637 mit der Bemerkung ein:

Nous auons naturellement plus d'admiration pour les choses qui sont au dessus de nous, que pour celles qui sont a pareille hauteur ou au dessous. [...] a cause qu'il faut tourner les yeux vers le ciel pour les regarder, nous

$122 \mathrm{Vgl}$. auch G. Hellanan, Die Meteorologie in den deutschen Flugschriften und Flugblättern des 16. Jabrbunderts: Ein Beitrag zur Geschichte der Meteorologie (« Abhandlungen der Preußischen Akademie der Wissenschaften, Physik.-math. Klasse », 1), Berlin 1921. Eindrückliche Zeugnisse hierfür in der Wolfenbütteler Sammlung frühneuzeitlicher - Einblattdrucke; vgl. Die Sammlung der Herzog August Bibliothek in Wolfenbüttel, Teil I:

Ethica, Physica, hrsg. von W. HARMs und M. Schilling ( des 16. und 17. Jahrhunderts », 1), Tübingen 1985.

${ }^{123}$ Zur literarischen Rezeption wissenschaftlich-meteorologischer Theorien und Kenntnisse vgl. S. K. Heninger jr., A Handbook of Renaissance Meteorology, Durham 1960. 
les imaginons si releuées, que mesme les Poëtes et les Peintres en composent le throsne de Dieu et font que là il employe ses propres mains a ouurir et fermer les portes des vens, a verser la rozée sur les fleurs, et a lancer la foudre sur les rochers. ${ }^{124}$

Doch die Rhetorik dieser Einleitung trügt; denn wie der Schluß der Météores belegt, war ihr erklärtes Ziel, die Bedeutungsdimension der atmosphärischen Erscheinungen ein für allemal mit einem reduktivistischen Mechanizismus hinwegzufegen. Auch Franz Reinzers Meteorologia philosophico-politica ist, wie wir gesehen haben, ein Werk, das in seinen naturwissenschaftlichen Quaestiones den Zeichen- oder gar Vorzeichencharakter der Himmelserscheinungen ausdrücklich negiert, diesbezüglichen Aberglauben aufs entschiedenste bekämpft und allenfalls am Rande - und selbst dann bloß in einem sehr vagen Sinne - physikotheologischen Argumenten Raum gibt: nicht mehr jedenfalls, als dies bereits in der Bibel angelegt ist. Úber das Lob des Schöpfers aus der Kontemplation Seiner Werke geht Reinzers natürliche Theologie nicht hinaus. Die Vorrede an den Leser schließt mit dem bemerkenswerten Zitat:

Non minus sapienter ac piè sagacissimus Meteororum contemplator Fromondus ${ }^{125}$ inquit: ideò natura, aut naturae Author DEUS haec prodigia coelestia, et mira in coelo phaenomena in alto suspendit, atque oculis nostris exposuit, ut suspiceremus Creatoris in mirabilibus Sapientiam et Majestatem. ${ }^{126}$

Sapientia und pietas, natura und naturae autor stehen einander wenn wohl auch nicht auf gleicher Stufe - als eigenständige Bereiche gegenüber. Eine Notwendigkeit, aus der Natur oder gar mit den Mitteln der Naturwissenschaft die providentia, ja existentia Gottes zu beweisen, gab es für den Jesuiten Reinzer nicht. Dies ist insofern bemerkenswert, als im protestantischen Bereich genau zur gleichen Zeit die Physikotheologie im engeren Sinne einsetzt, die sich mit Vorliebe meteorologischklimatologischer Argumente bediente und eben dies sich zur Aufgabe gemacht hatte: den naturwissenschaftlichen Gottesbeweis durch funktionale Úberhöhung der kausalmechanischen Betrachtungsweise zu führen, nachdem und gerade weil sich die alte Naturtheologie erschöpft hatte. ${ }^{17}$

124 R. Descartes, Les météores, in Oeuvres (wie Anm. 112), VI, Paris 1902, S. 231.

125 L. FroIdmont, Meteorologicorum libri VI, Löwen 1627.

126 Meteorologia (1698), fol. $†$.

127 Vgl. hierzu bes. M. Bürtner, Protestantische Theologie und Klimatologie im 18. Jabrhundert, "Neue Zeitschrift für systematische Theologie und Religionsphilosophie », 6, 1964, S. 155.191; wiederabgedruckt in Zur Entwicklung der Geographie vom Mittelalter bis zu Carl Ritter, hrsg. von M. BüTTNER ( «Abhandlungen und Quellen zur Geschichte der Geographie und Kosmologie », 3), Paderborn-München-Wien-Zürich 1982, S. 183-217. 
Der Unterschied zur Physikotheologie einerseits und zum Cartesischen Reduktivismus andererseits wird deutlich, wenn man sieht, in welcher Weise Reinzer den meteora emblematische Funktion zuweist. Nicht die Theologie und die Erkenntnis Gottes sind es, auf die das atmosphärische Geschehen bezogen ist, sondern Ethik und politische Moral. Was die Verquickung von Meteorologie und Ethik angeht, standen ihm hierbei natürlich Senecas Naturales quaestiones als literarisches Vorbild vor Augen, ein Werk, das vorwiegend den atmosphärischen Erscheinungen gewidmet ist und sich, wie alle Schriften dieses vermeintlich dem Christentum nahestehenden Stoikers, im 17. Jahrhundert größter Popularität erfreute. Bekanntlich war es gerade das neuerwachte Interesse an der stoischen Ethik, das zu jener Zeit auch die Physik der Stoa als eine Alternative zum Aristotelismus wieder höchst aktuell erscheinen ließ. ${ }^{128}$ Franz Reinzer zitiert Seneca als naturwissenschaftlichen Gewährsmann häufig und gern; aber auch als Moralist galt er ihm viel, wie die von Reinzer unter dem Titel Seneca christianus (Passau 1700) herausgegebene Blütenlese aus den Epistolae morales belegt. Was nun die Naturales quaestiones auszeichnet und sie mit dem didaktischen Anliegen Reinzers verbindet, ist der Umstand, daß auch bei Seneca Naturforschung als Einsicht in die göttliche Weltordnung niemals Selbstzweck ist, sondern darauf zielt, weltanschauliche Orientierung zu bieten. Als Naturwissenschaftler war Seneca vor allem Moralist, der sich gegen den Materialismus der griechischen Naturphilosophie wandte und eine "Spiritualisierung " der Naturerkenntnis suchte. ${ }^{29}$ "Omnibus rebus omnibusque sermonibus aliquid salutare miscendum est $\gg,{ }^{130}$ hieß ein Grundsatz der in den Naturales quaestiones gewählten Darstellungsart. Doch anders als Seneca, für den Naturerkenntnis in Gotteserkenntnis und Selbsterkenntnis mündete, ist Reinzer weniger philosophisch und weniger spirituell, dafür mehr auf praktische Moral und politisches Handeln aus, und auf dieses Ziel richtet er die moralisierende Naturbetrachtung seiner Meteorologia philosopbico-politica. Dahinter steht ein, wenn man so will, didaktisches Konzept, Weltweisheit und Morallehre so $\mathrm{zu}$ verbinden, daß beide zur Grundlage verantwortlichen

128 Vgl. P. Barker und B. R. Goldstein, Is Seventeenth-Century Physics indebted to the Stoics?, "Centaurus ", 27, 1984, S. 148-164.

129 Vgl. G. Stahl, Die 'Naturales Quaestiones' Senecas: Ein Beitrag zum Spiritualisierungsprozeß der römischen Stoa, "Hermes, Zeitschrift für Klassische Philologie ", 92, 1964, S. 425-454; wiederabgedruckt in Seneca als Philosoph, hrsg. von G. MaURACH ( « Wege der Forschung », 414), Darmstadt 1975, S. 264-304. Hierin auch weitere Beiträge zu den wissenschaftsgeschichtlich nicht unumstrittenen Naturales quaestiones.

130 SeneCA, Nat. quaest. II, 59, 2. 
Handelns werden können. Er habe deshalb, so wendet Reinzer sich an den Leser,

auch denen Meteorologischen Sätzen/ wie es nemlich der Sachen Ordnung erforderte/ eine Politische Schluß=Rede/ darmit wir mit dem Philosopho geschicklich reden/ und mit dem Politico uns klüglich verhalten und aufführen möchten/ beygefüget: Dann dieses ist der kräftigste Schluß/ dessen Vorder= Sätze nicht nur sich auf eine natürliche/ sondern auch sittliche Philosophie, die man in einer Schule zugleich lehret/ gründen und stützen. ${ }^{131}$

Was lag näher, als diese Botschaft in die Form eines Fürstenspiegels zu kleiden, den man dem Landesherren als dem Garanten von Weltund Staatsweisheit widmete. Doch hätten sich Blitz und Donner, Kometen und Quellflüsse selbst in der Blütezeit des absolutistischen Gedankens schwerlich als Epiphanie des Herrschers begreifen lassen. Reinzer wählt deshalb das Mittel der Analogie, um unter Verweis auf die Weisheit, die Ókonomie und die Ordnung der Natur seine politischmoralische Botschaft zu übermitteln. Beide Bereiche, Natur und Politik, bleiben dabei - auch in der Darstellung - klar unterschieden und finden erst im didaktischen Objekt, dem gelehrten Politiker oder politischen Gelehrten wieder zusammen.

An einigen Beispielen, die auch den Stil der emblematischen Abschnitte belegen mögen, sei das analogische Vorgehen illustriert: In der zweiten Quaestio der letzten, den Mineralien und Metallen gewidmeten Dissertatio handelt Reinzer von den mineralischen Ausscheidungen der Erde und insbesondere vom Salz, das zunächst unter ausgiebiger Verwendung der Descartesschen Météores ganz nüchtern, ja geradezu schulmäßigtrocken nach seinen stofflichen Eigenschaften abgehandelt wird. Ausführlich ist von Gebrauch und Nutzen des Salzes die Rede (s. Abb. 4). Daran schließt sich die zugehörige Politische Schluß $\beta=$ Rede an, die Reinzer unter die Uberschrift stellt: « Ein Staat empfähet seinen grösten Nutzen von guten Künsten und Wissenschaften ». Nun wird unter reichlicher Verwendung literarischer Belegstellen die Wissenschaft als das wahre Salz eines Staates herausgestellt und ihre Förderung dem Herrscher besonders anempfohlen.

Hinweg mit der Bäurischen/ und von dem Acker $=$ Wesen hergenommnen Meinung! die der zum Pflug gebohrne und aufferzogne C. Valerius Licinius geführet: Nemlich/gute Künsten und Wissenschaften seyen der Republiquen

131 Meteorologia (1712), fol. )(2v.

132 Meteorologia (1712), S. 359. 
Pestilentz. [...] Auf was für einem Grund das gemeine Wesen bestehen; durch was für Mittlen ein Politischer Staat zu erhalten; und wie die Höfe und Rath = Häuser gezieret werden sollen; das last uns von dem Ungarischen König Ladislao vernehmen. Derselbe versicherte; daß er den für keinen Menschen hielte/ welcher nicht studiret hätte. [...] Das Saltz ist des gemeinen Lebens Unterhalt; und die Wissenschafften seynd eine Blüthe der Weißheit. Das Saltz verwahret die todte Leichnam vor der Fäulung; und das Leben ohne Wissenschafften ist ein Todt/ und ein Grab eines lebendigen Menschen. Derjenige Leib ist ohne Haupt/ so von einem Haupt regieret wird worinnen keine Weißheit befindlich: dann es ist ein Haupt=Schade wann man van einem Haupt regieret wird/ das kein Hirn hat. ${ }^{132}[\ldots]$

Dem Haupt so über die Glieder herrschet/ stehet insonderheit zu/ daß es mit Wissenschafften begabt seye: dann diese letztre seynd ein Perlen= Schmuck/ womit seine Krone ausgezieret wird. [...] An einem Fürsten stehet es grund=übel/ wann er durch andere reden muß; da doch des Landes Wohlfahrt auf ihm ruhen soll. Seynd die Kronen schwer/ so mögen sie am besten von einem weisen und klugen Haupt getragen werden. ${ }^{133}$

Freilich beläßt Reinzer es nicht bei Allgemeinplätzen, sondern gibt literarisch verbrämt immer wieder auch konkrete Hinweise, wie Wissenschaft dem Staate nutzbar werden könne. Dies bleibt nicht auf die Naturwissenschaften beschränkt. So heißt es im Anschluß an die Behandlung des Silbers und seiner Eigenschaften als Conclusio politica, die fürstliche Rentkammer dürfe niemals leerstehen, noch dürfe sie dazu dienen, eitle Schätze zu horten, sondern müsse ihr Silber « zum Nutzen des gemeinen Wesens » wieder im Umlauf bringen, und nun folgen einige Grundsätze der Geldwirtschaft. Es versteht sich von selbst, daß die politischen Ratschläge Reinzers zumeist von der Art sind, wie sie Politikern seit jeher am leichtesten ins Ohr gehen:

Obschon die Wissenschafften keine Waffen schmidten/ so schmidten sie doch gute Rathschläge/ damit die erstere nicht ohnbedächtlich ergriffen werden. [...] Wissenschafft und Krieg stehen wohl beysammen: ohne Wissenschafft ist der Krieg ein barbarisches Wesen; und ohne den Krieg ist die Wissenschafft elend und verächtlich. ${ }^{134}$

Natürlich weiß Reinzer als Professor am Akademischen Gymnasium zu Linz auch das probate Mittel, die Förderung der Wissenschaften zum

- 133 Meteorologia (1712), S. 360.

134 Meteorologia (1712), S. 361. Ähnlich heißt es auch im Anschluß an die Abhandlung über das Eisen zur Pictura einer Rüstkammer \& In Friedens = Zeiten soll man auch an den Krieg gedencken », Meteorologia (1712), S. 421. 
Wohle Osterreichs zu bewerkstelligen. Es sind die Schulen und ihre Lehrer, die dem Landesherren ans Herz gelegt werden. Im Anschluß an den Abschnitt, in dem Reinzer die Transmutation der Metalle und insbesondere die Verwandlung unedeler Erze in wahres Gold bespricht und diese Möglichkeit prinzipiell bejaht, wenn auch für aussichtlos und wenig lohnend hält, kommt er unter der Uberschrift Juventutis institutio Reipublicae perutilis auf die wahrhaft der Mühe verlohnende Transmutation des Menschen durch Bildung. ${ }^{135}$ Natürlich spielt Reinzer hier mehr oder minder unverhüllt auf die alchemistischen Neigungen am Wiener Hofe ${ }^{136}$ an und bedeutet dem Kaiser, auf den die Mahnung gemünzt sein dürfte, wie das an vorgebliche Adepten verschwendete Vermögen wirkungsvoller zu verwenden sei: So wie der Alchemist den Goldsamen in wertloses Metall einsenke und dieses damit in pures Gold verwandle, müsse der Erzieher den von der Natur in die Jugend eingesenkten Tugendsamen zur Entwicklung bringen. Dafür aber gebe es kein besseres Rezept als die Errichtung guter Schulen und die Anstellung befähigter Lehrer. Dies käme nicht bloß den Wissenschaften, sondern auch den machtpolitischen Interessen des Landes zugute, weil ein gebildetes Staatswesen am längsten Bestand habe: «Der Unterthanen Gemüther lassen sich nicht ehender/ als durch Künste und Wissenschafften bezähmen: und aus diesem Trojanischen Pferd kommen zu Kriegs = und Friedens=Zeiten berühmte Helden her ${ }^{137}$ Natürlich läßt Reinzer sich die Gelegenheit nicht nehmen, den nervus rerum der Wissenschaftsförderung beim Namen zu nennen; denn wo die Gelehrsamkeit in Flor gehalten werden soll, da « muß man sich mit Belohnungen/ wodurch die Gemüther anzulocken seyn/ nicht sparsam erzeigen $\gg .{ }^{138}$

Es führte zu weit und wäre wohl auch in höchstem Maße ermüdend, die blumenreichen Conclusiones politicae im einzelnen vorzustellen. Es sind gelehrte Florilegien von loci communes aus der antiken Literatur und Poesie, angereichert durch historische Exempel aus der Geschichte des Hauses Habsburg und immer wieder auf Person und Neigungen des Römischen Königs Josephs I. und seines Vaters, des Kaisers Leopolds I., bezogen. So heißt es etwa im Anschluß an die Abhandlung der Haloerscheinungen und Nebensonnen:

Das Firmament wird zu weilen von einer doppelten Sonne beleuchtet:

135 Meteorologia (1712), S. 400-402.

136 Vgl. H. Ritter von SBrik, Abenteurer am Hofe Kaiser Leopolds I., « Archiv für Kulturgeschichte $», 8,1910$, S. 52-71.

137 Meteorologia (1712), S. 401.

138 Meteorologia (1712), S. 401-402. 
Leopoldus scheinet als eine doppelte Sonne/ wann er sich in dem Sohn/ und der Sohn in dem Vatter beschauet. [...]

Des Vatters Tugend soll den Sohn zur Nachfolg treiben;

Dann wird er dem/ der ihn gezeuget/ ähnlich bleiben. ${ }^{139}$

In gleicher Manier sind in allen 83 Quaestiones und Conclusiones Naturerscheinung und gesellschaftliche Wirklichkeit, naturwissenschaftliche Erklärung und politische Moral in Beziehung gebracht. Dabei tendiert Reinzer dazu, in der Ethik den Ausgleich zu predigen, der auch im atmosphärischen Geschehen als temperatura, als gleichmäßige Mischung der Qualitäten, am zuträglichsten ist. Nicht zu streng und nicht zu gütig, nicht geizig und nicht verschwenderisch, grausam wo nötig und milde wo möglich soll der ideale Herrscher sein, wie es die Fanfaren timore und amore im Titelkupfer der Meteorologia philosopbico-politica (s. Abb. 1) verkünden.

Die Theorie der Mischung findet ihr Pendant in der anatbymiasisLehre der Meteorologie: Weisheit und Tugend als Ingredienzien zum politischen Aufstieg des Monarchen entsprechen den Ausdünstungen von Erde und Wasser, aus denen sich alle Erscheinungen im sublimen Bereich des Luftraums erklären. In der Conclusio politica zur ersten Pictura (Abb. 2) heißt es unter dem Motto Singula de binis:

Gleichwie die Erde ihre neblichte Gebuhrten an die Lufft treibet/ und das Wasser seine Dämpffe über sich nach der Höhe schicket/ damit sie allda von der Sonnen/ die als der Ursprung der Luff $=$ Würckungen/ selbige entzündet und erleuchtet/ zu einem schönen Regen=Bogen gemacht/ oder zu Donner $=$ Keulen gehärtet werden möchten: Dann von solchen beyden entstehen alle Lufft $=$ Zeichen/ und alle Meteorische Gestalten in der Lufft. Eben also steiget auch ein Politicus mit Hülff der Tugend und der Weißheit in die Höhe/ damit er leuchte und brenne; nem[1]ich damit er/ indem er von Weißheit helle leuchtet/ wohl regiere; und indem er von Tugend brennet/ glücklich lebe.

Aëra foecundat Fumis terra, unde Vapore;

fulminis hinc ignes, Iridis inde color.

Qui Virtute ardent, et queis Sapientia lux est;

Quàm benè sceptra regunt, quàm sine labe manent!

Das Wasser lasset Dampff/ die Erde Dünst' auffsteigen/

Und diese zieht die Sonn' hin nach der hohen Lufft; 
Drauff pflegt der bunte Schein des Bogens sich zu zeigen/

Und der entbrannte Blitz strahlt in die tieffste Grufft.

Weißheit und Tugend muß dich in die Höhe heben;

Dann wird dein Amt ein Licht/ ein Glantz dein ehrbar Leben.

Es charakterisiert die moralisierende Tendenz von Reinzers Meteorologia philosophico-politica, wenn elektrisierter Bernstein und Magnet als Emblemata des guten Fürsten erscheinen. Wie der Magnetstein, der - in den Klauen eines Adlers - die Studierstube des Naturforschers ziert (Pictura 78, s. Abb. 5), verstreute Eisenringe zur Kette zusammenfügt, ${ }^{140}$ so soll der Fürst kraft seiner Weisheit und Stärke unter den Untertanen seines Reiches Eintracht und Frieden vermitteln; und wie der kostbare Bernstein das elende Stroh anzieht, soll sich der Reiche und Mächtige der Armen und Niedrigen annehmen.

Die Frage drängt sich auf, inwieweit Reinzer mit dieser Analogisierung von Naturgesetz und politischem Moralgesetz, die seiner emblematischen Meteorologie als Formprinzip zugrundeliegt, bewußt $\mathrm{Na}$ turrechtslehren des 17. Jahrhunderts aufgreift, wie sie etwa der große holländische Rechtslehrer Hugo Grotius formuliert hatte. Am Linzer Akademischen Gymnasium mit seiner juristischen Schwerpunktbildung dürfte man mit der Grotiusschen Rechtsauffassung vertraut gewesen sein. Leider geht Reinzer auf solche Zusammenhänge nicht explizit ein, doch verweist die Art und Weise, in der er die Natur und ihre Gesetze zum Beispiel und Maßstab des Gesellschaftlichen macht, klar auf $\mathrm{Na}$ turrechtsvorstellungen seiner Zeit und nimmt die dann für die Aufklärung verbindliche Gleichsetzung von Natur und Vernunft vorweg.

\subsection{Die Picturae und ibre Stecher}

Es sind die Picturae, jene 83 in den Text eingefügten Kupferstiche, die die Verbindung zwischen den sachlich-naturwissenschaftlichen Quaestiones und den blumenreichen Conclusiones politicae herstellen. Im Bilde greifen sie den zuvor behandelten Gegenstand noch einmal auf und erfüllen in dieser Hinsicht durchaus die Funktion einer naturwissenschaftlichen Abbildung, die in Worten nur schwer zu beschreibende Gegenstände bildlich vor Augen führt. Zugleich aber ist das naturwissenschaftliche Objekt nun in eine Szenerie plaziert, die ihm Bedeutung im

10 Ein Versuch, der schon bei LuKrez, De rerum natura 6, 910-915, erscheint. 
menschlichen Leben zuweist, und fordert die Inscriptio des Innenrahmens die nachfolgende Deutung des Dargestellten und dieser Zusammenhänge heraus.

Thematisch und stilistisch herrscht große Vielfalt. Die Bildinhalte reichen von rein naturkundlichen Abbildungen vorfindlicher Realität über gewerbliches Tun und höfisches Treiben bis hin zur Allegorie, wo die meteorologische res picta bisweilen nur noch am Rande aufscheint. Die größte Gruppe bilden Darstellungen aus dem bürgerlichen Leben, Handwerk und Landbau (14 Picturae), gefolgt von Architekturveduten (Paläste und Städte, meist in Zusammenhang mit der Darstellung von Unwetter, Blitzschlag oder Erdbeben, 13 Picturae), Naturszenen (12), Schiffahrt (9), Höfisches Leben (8), Krieg (6), Mythologie und biblische Geschichte (5), feurige Himmelserscheinungen (5), Allegorische Natur (4) und Wissenschaft (3). Motivisch eher konventionell, sind die Picturae kompositorisch nicht ungeschickt und recht fein ausgeführt. Innerhalb der Emblembücher stehen sie, was ihren künstlerischen Wert angeht, durchaus über dem Durchschnitt.

Wie schon erwähnt, dürfte das gesamte Bildprogramm der Meteorologia philosophico-politica von dem Linzer Maler Wolfgang Joseph Kadoriza herrühren, auch wenn dieser nur das allegorische Titelkupfer und die Picturae 36, 40, 44 und 48-83 namentlich signiert hat. Doch taucht der Name keines anderen Zeichners auf. Der ungewöhnlich enge und vielschichtige Zusammenhang zwischen Texten und Bildern legt den Schluß nahe, daß das Bildprogramm in enger Zusammenarbeit zwischen Reinzer und Kadoriza entstanden sei, so daß dieser mit Recht zu den Autoren des Werkes zu zählen wäre. Es ist keine Frage, daß von einem Primat der res picta, des vorgefundenen Naturbildes, wie es die Emblemtheorie gelegentlich fordert, im Falle der Meteorologia philosophicopolitica keine Rede sein kann. Hier ist eindeutig zunächst der Text geschrieben und nach diesem dann die Pictura komponiert. Sie ist voll versteckter Textzitate, die nicht nur die nachfolgenden Conclusiones politicae, sondern auch die vorangestellten naturwissenschaftlichen Quaestiones mit einbeziehen. Kein Zweifel, daß Reinzer an der Konzeption des Bildprogrammes selbst beteiligt war; zumindest wird er seinem Zeichner die Vorlagen zur Verfügung gestellt haben, nach denen dieser Naturkundliches zu zeichnen hatte. In der Tat sind die Motive in einigen Fällen den Abbildungen der gelehrten Literatur entnommen, die Reinzer für den naturwissenschaftlich-meteorologischen Teil benutzt und zitiert hat. Dies kann hier nur an zwei Beispielen gezeigt werden, wo Kadoriza im einen Fall die doppelblattgroße Darstellung der unterirdischen Feuerherde aus Athanasius Kirchers Mundus subterraneus nahezu unverändert 
und lediglich dem kleineren Format zuliebe vereinfacht kopiert (Abb. 6a-b), im anderen Fall eine Abbildung des Verlaufs unterirdischer Erzgänge aus dem gleichen Werk mit einer Vorlage aus Georg Agricolas De re metallica kombiniert (Abb. 7a-c). So werden auch die Unterschiede in Qualität und Manier der Picturae eher auf technische und künstlerische Unterschiede der Vorlagen als auf die unterschiedliche Begabung derjenigen zurückzuführen sein, die die Zeichnungen Kadorizas in Kupfer gestochen haben.

Vier Künstler lassen sich als Stecher nachweisen; alle haben in Augsburg und für den Kupferstichverleger Jeremias Wolff gearbeitet. Zunächst Andreas Matthäus Wolfgang (1660-1736) aus Chemnitz, der seit 1691 in Augsburg als Kupferstecher arbeitete und hauptsächlich Bildnisse, Schlachtenfolgen und Architekturdarstellungen stach. ${ }^{141}$ Von ihm stammt das großformatige Titelkupfer (Abb. 1). Jakob Müller (um 1630-1703), ein Veduten- und Portraitstecher, ${ }^{142}$ hat in Reinzers Meteorologia philosopbico-politica nur die erste Pictura (Abb. 2) in der Platte signiert. Wahrscheinlich wurde gleich darauf Johann Stri(e)dbeck d.J. (1665-1714) mit der Fortführung des Auftrages betraut; denn er signierte oder monogrammierte die Picturae 3, 13, 18, 20, 24 und 40. Kunstgeschichtlich ist er als Zeichner und Stecher von Wappen und Trachtenbildern bekannt. ${ }^{143}$ Von Pictura 42 an wurde die Arbeit dann von der begabten Johanna Sybilla Küsel (1650-1717) ${ }^{144}$ fortgeführt, die 1685 einen Johann Ulrich Krauß geheiratet hatte und 15 der verbleibenden 42 Kupfertafeln mit ihrem J(obanna) S(ybilla) K(rausen) f(ecit) bezeichnete. Sie stammte aus einer Augsburger Stecher- und Goldschmiedefamilie und hat sich mit ihrer technischen Virtuosität beim Kopieren einen Namen gemacht. Die übrigen Picturae sind nicht monogrammiert oder weisen bloß Kadoriza als Zeichner der Vorlagen aus. ${ }^{145}$

\subsection{Die Meteorologia philosophico-politica in der Emblembuchtradition}

Auch wenn Franz Reinzers Meteorologia philosophico-politica in formaler wie inhaltlicher Hinsicht die Grenzen des traditionellen Em-

141 ThIEME-Becker (wie Anm. 14), 36 (1947), S. 221.

142 Thieme-Becker (wie Anm. 14), 25 (1931), S. 232.

143 Thieme-Becker (wie Anm. 14), 32 (1938), S. 185-186.

144 Thieme-Becker (wie Anm. 14), 32 (1928), S. 74.

145 Die unbezeichneten Picturac aufgrund stilistischer Merkmale bestimmten Stechern zuzuweisen, erscheint nicht möglich. 


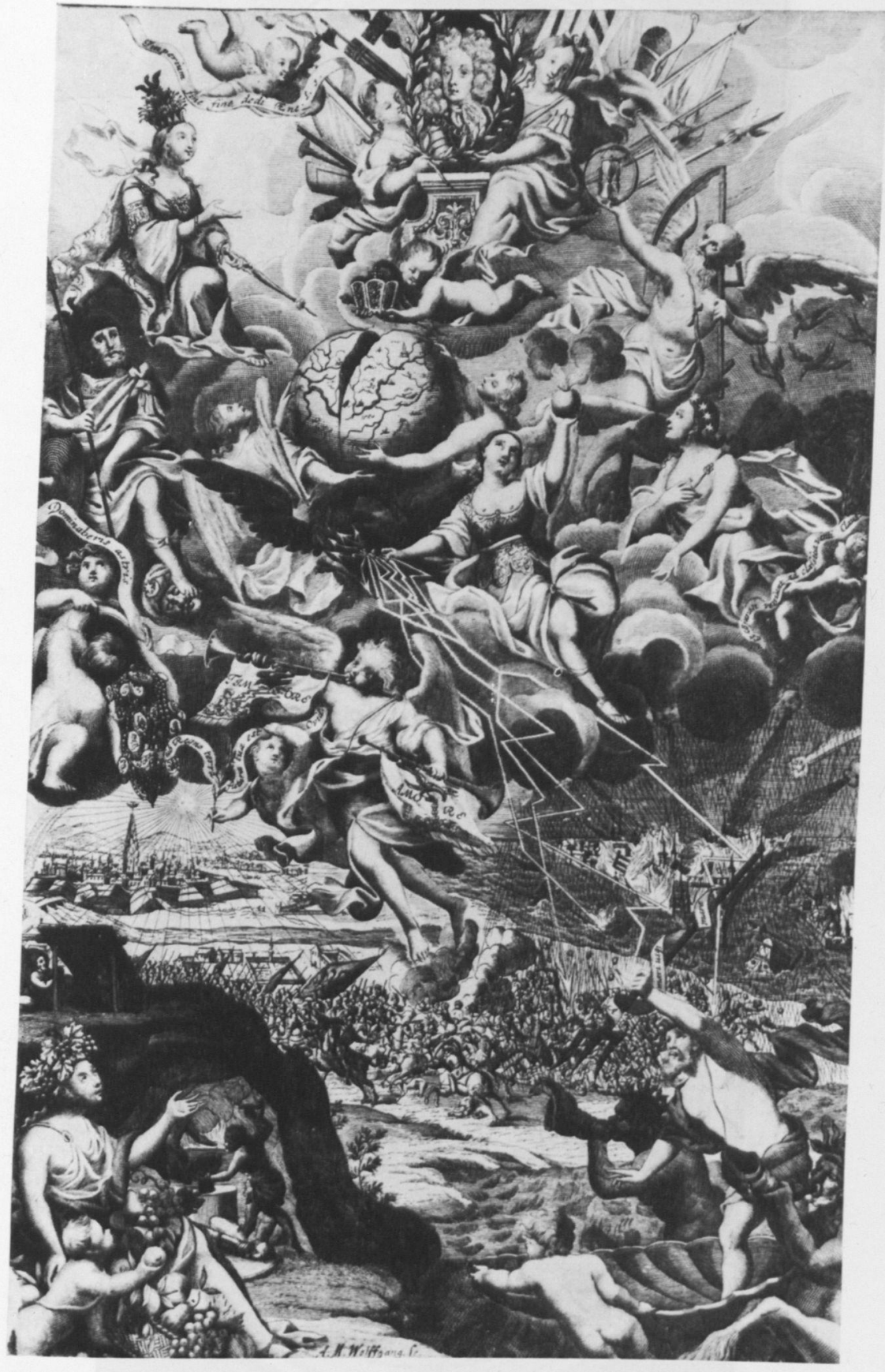

Abb. 1. - Titelkupfer, Meteorologia (1698), $295 \times 185 \mathrm{~mm}$, bez. Wolfgangus Josephus Kadoriza del. Lincij / A. M. Wolffgang sc., letzter (= dritter) Druckzustand. (Alle Abbildungen nach dem Exemplar der Staats- und Universitätsbibliothek Hamburg). 


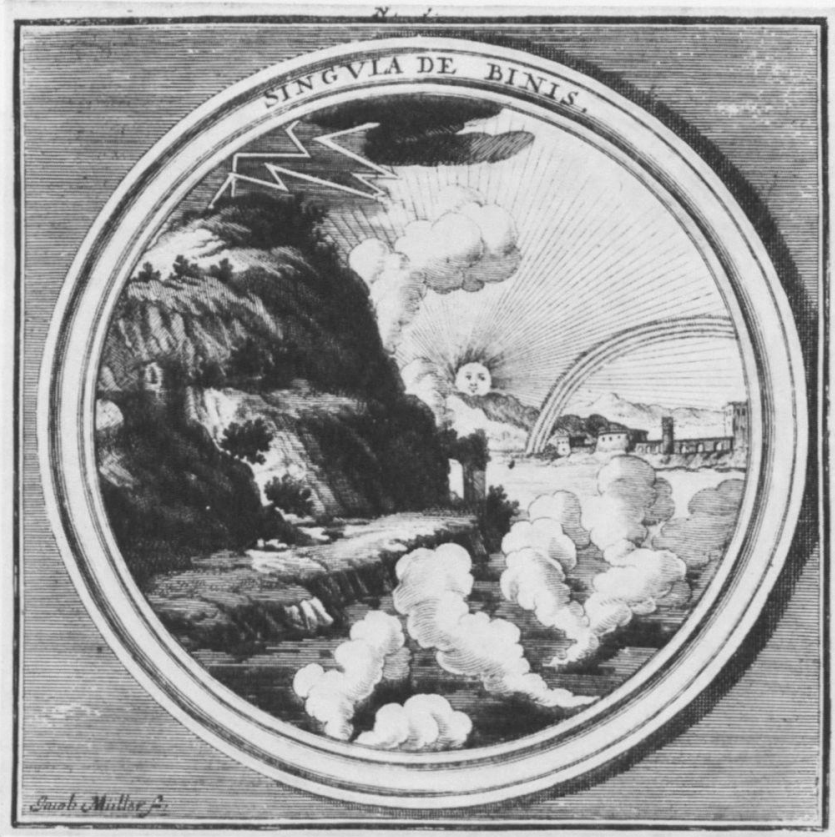

Abb. 2. - Pictura 1, Meteorologia (1698), S. 4, bez. Jacob Müller f.; zu Diss. I, Quaest. I: Politicus scientiâ et virtute praestet. So wie die meteorischen Erscheinungen aus feuchten und trockenen Dünsten emporsteigen, soll sich der Staatsmann durch Gelehrsamkeit und Tugend auszeichnen.

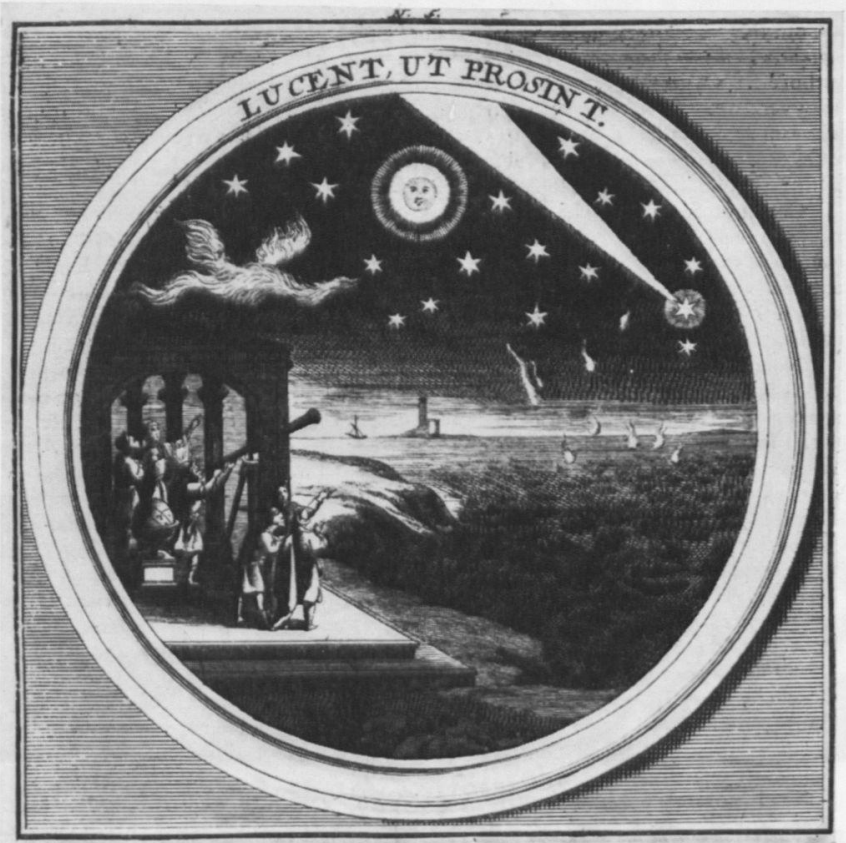

Abb. 3. - Pictura 5, Meteorologia (1698), S. 16, unbez.; zu Diss. I, Quaest. V: Praesit, ut prosit politicus. Die feurigen Himmelserscheinungen sind so hoch erhaben, nicht um zu schrecken, sondern um zu nützen, indem sie die Luft rein und die Erde fruchtbar machen. 


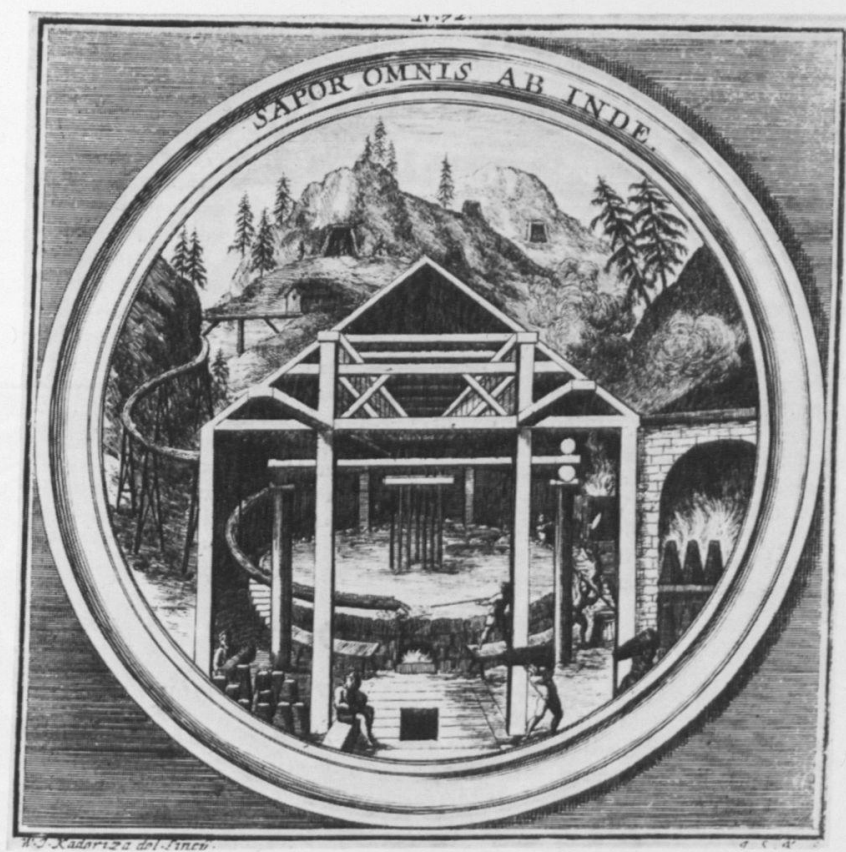

Abb. 4. - Pictura 72, Meteorologia (1698), S. 251, bez. W. J. Kadoriza del. Lincij / J. S. K. f.; zu Diss. XII, Quaest. II: Maximum Reipubl[icae] bonum à litteris. Die Wissenschaft als Salz der Menschheit. (Dargestellt ist eine Salzsiederei; in der zugehörigen Quaestio ist auf die Salzgewinnung in Tirol und der Steiermark verwiesen).

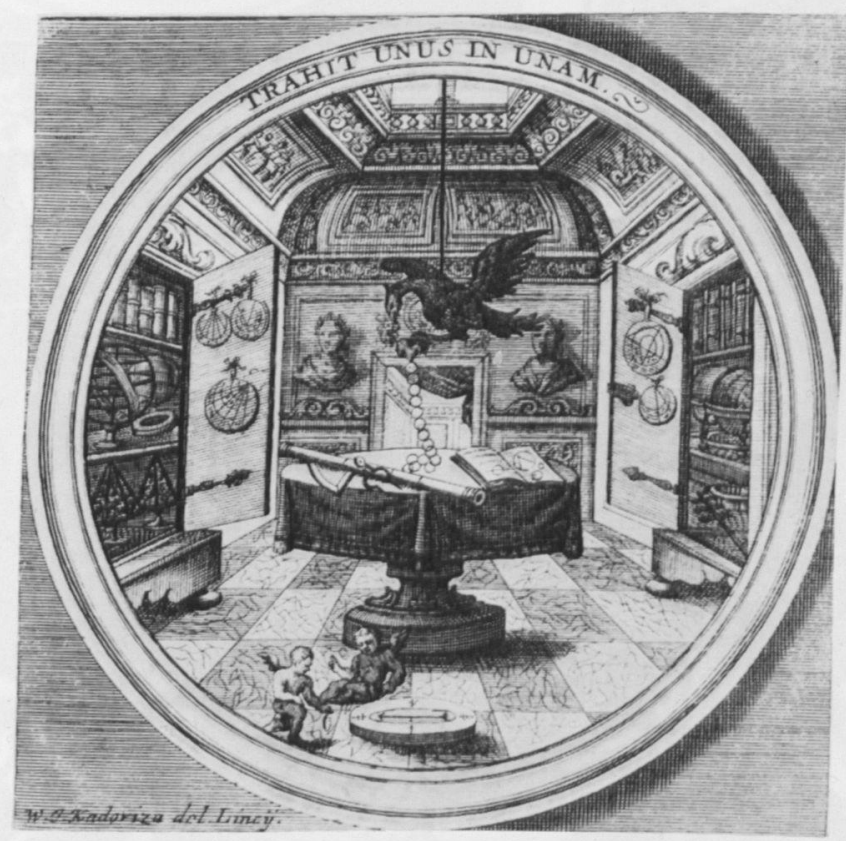

Abb. 5. - Pictura 78, Meteorologia (1698), S. 276, bez. W. J. Kadoriza del. Lincij; zu Diss. XII, Quaest. VIII: Concordiae summoperè studendum Politico. Wie der Magnet lose Eisenringe zur Kette zusammenfügt, soll der Politiker Zusammenhalt und Eintracht stiften. 


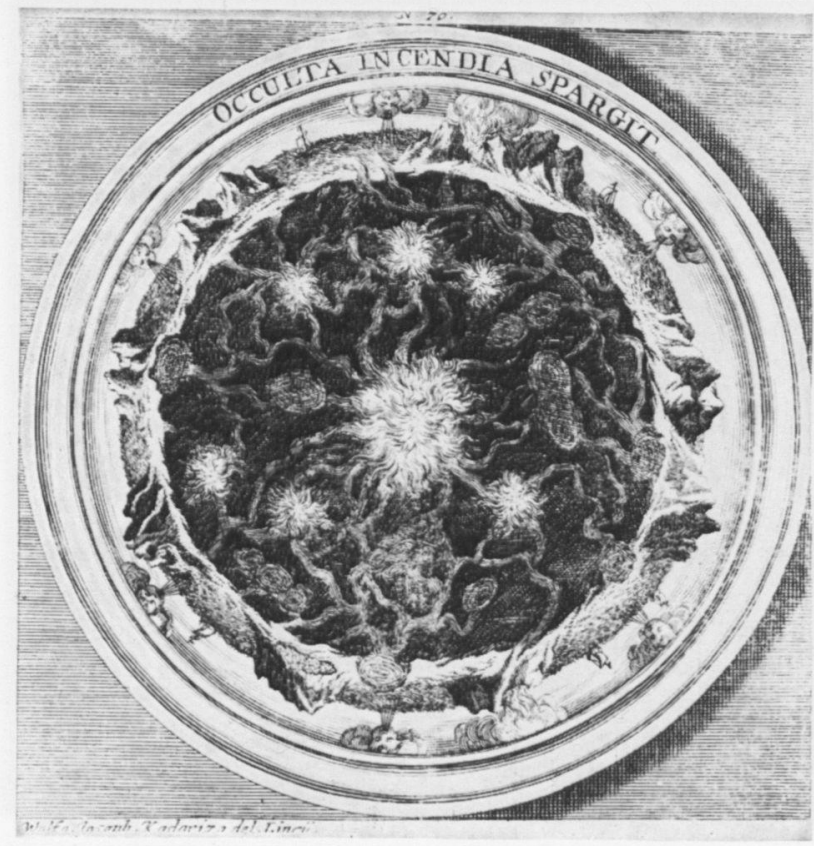

Abb. 6a. - Pictura 70, Meteorologia (1698), S. 243, bez. Wolffg. Joseph Kadoriza del. Lincij; zu Diss. XI, Quaest. III: Immoderatus animi fervor ad intra coërcendus. Wie die Erde ihr inneres Feuer bedeckt, damit es sich nicht zum Weltenbrand weitet, soll auch der Herrscher sein Gemüt bezähmen.

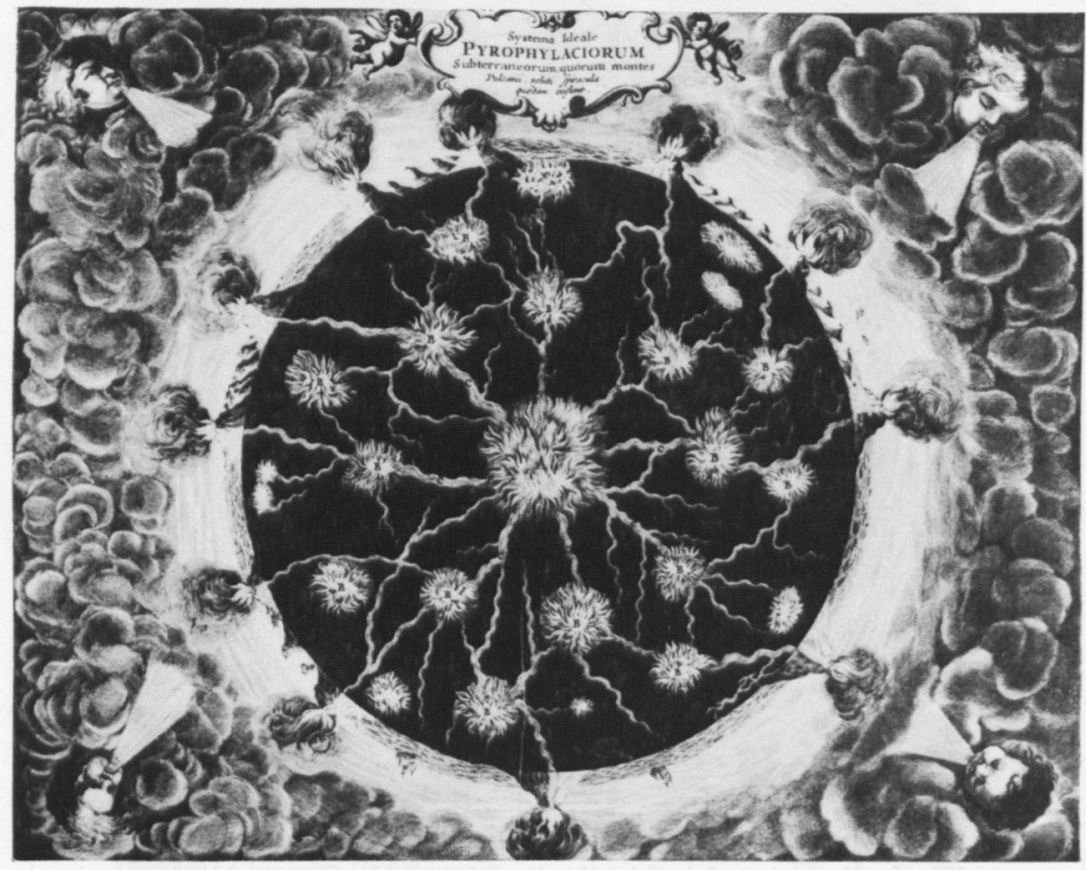

Abb. 6b. - Die Erde mit unterirdischen Feuerherden, Vulkanen und Winden, Kupferstich, $360 \times 414$ mm, aus: Athanasius Kircher, Mundus subterraneus, Amsterdam 1665, Bd. I., nach S. 180. 


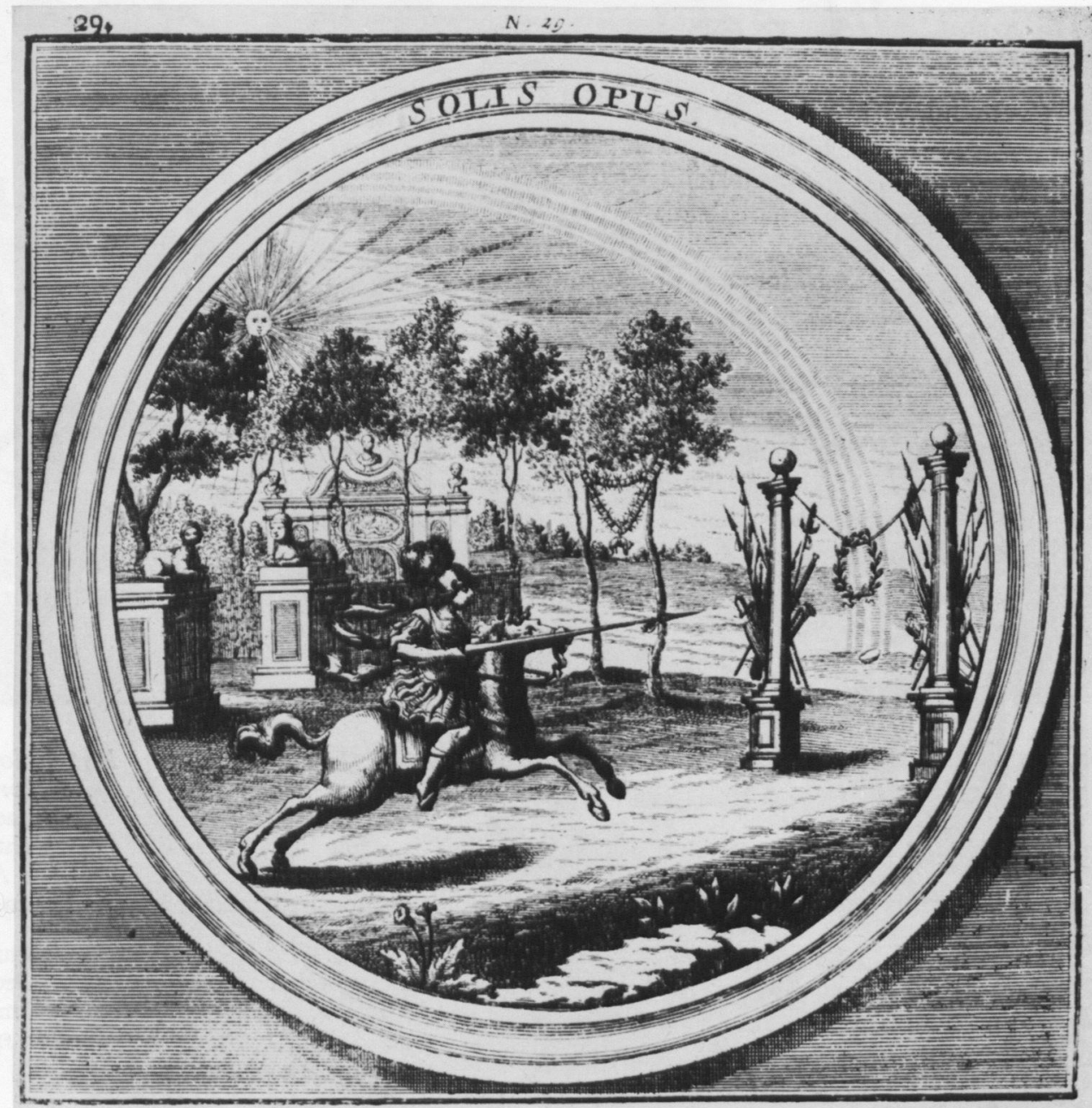

Abb. 8. - Pictura 29, Meteorologia (1698), S. 95, unbez.; zu Diss. V, Quaest. VI: Sanguinis claritas factis probanda. Der Glanz der Sonne ist Ursache des Regenbogens, die Taten eines Herrschers Zeugnis seiner edlen Abstammung. 
blembuchs sprengt, weist das Werk Züge auf, die es mit der deutschen Jesuitenemblematik ${ }^{146}$ des 17 . Jahrhunderts verbinden.

Von Mitgliedern der Gesellschaft Jesu verfaßte Emblembücher tauchen erst relativ spät auf. Als das erste Werk dieser Art, Jakob Spanmüllers Floridor 1595 in Augsburg erschien, hatte die Flut der Emblemata bereits ihren Höhepunkt erreicht. Sehr rasch aber haben es die Jesuiten verstanden, sich des allseits beliebten Genres mit seiner eingängigen Mischung aus Nützlichem und Gefälligem zu bedienen, um ihren religiösen und erzieherischen Auftrag durchzusetzen. In der Tat zählen die Emblembücher zu den erfolgreichsten Werken aus dem propagandistischen Schrifttum der Gesellschaft. ${ }^{147}$ In der Rhetorik, der Dramaturgie und den geistlichen Exerzitien der Jesuiten spielte die Überzeugungskraft des Bildes eine zentrale Rolle, ja ist das Bild als Argument erst eigentlich entdeckt worden. ${ }^{148}$ Denn über Bild und Text, Gemüt und Verstand ließen sich nicht nur die breiteren Schichten der Gläubigen, sondern gerade auch die Großen und Mächtigen im Lande erreichen. In besonderem $\mathrm{Maße}$ haben sich in dieser Hinsicht die holländischen und deutschen Provinzen hervorgetan, und unter diesen wiederum ragen die österreichische und die oberdeutsche Provinz der Gesellschaft mit den Druckorten Wien, Graz und Linz bzw. München, Augsburg und Dillingen deutlich heraus. ${ }^{149}$ Die thematische Vielfalt der von Jesuiten verfaßten Emblembücher ist groß. Dimler klassifiziert sie in heroische (mit heraldischen, höfischen und politischen Motiven), theologische (vor allem Andachtsbücher, Marienleben, Memento mori) und didaktische (bei denen enzyklopädische, kosmologische und rhetorische an erster Stelle stehen). Oft handelt es sich um kollektive Werke aus den Kollegien und Universitäten des Ordens. Der Höhepunkt der Jesuitenemblematik liegt zwischen 1670 und 1700; anschließend trat rascher Niedergang ein. Dabei scheint es ein besonderes Kennzeichen der österreichischen Jesuitenemblematik gewesen $z u$ sein, daß die sonst so reichlich vertretenen theologischen Werke ganz fehlen. ${ }^{150}$ Entsprechend dem Auftrag und der

146 Vgl. Dimler (wie Anm. 8); sowie G. R. Dimler, Jesuit Emblems: Implications for the Index Emblematicus, in The European Emblem: Towards an Index Emblematicus, hrsg. von P. M. DALY, Waterloo 1980, S. 109-120. Die von Dimler vorgeschlagene Typologie paßt freilich nicht auf die Meteorologia philosophico-politica.

$147 \mathrm{Vgl}$. PrAz (wie Anm. 8), S. 170.

$148 \mathrm{Vgl}$. B. BAUER, Das Bild als Argument: Emblematiscbe Kulissen in den Bübnenmeditationen Franciscus Langs, "Archiv für Kulturgeschichte», 64, 1982, S. 79-170.

$149 \mathrm{Vgl}$. Dimler (wie Anm. 8); sowie G. R. Dimler, A Bibliographical Survey of Emblem Books produced by Jesuit Colleges in the early Society: Topography and Themes, "Archivum historicum Societatis Jesu », 48, 1979, S. 297-309.

$150 \mathrm{Vgl}$. Dimler (wie Anm. 8), S. 132. 
politischen Rolle der Gesellschaft war die Zahl ihrer Emblembücher, die weltlichen Herrschern gewidmet war, hier wie in anderen katholischen Territorien auffällig hoch, ${ }^{151}$ wenn auch ausgesprochene Fürstenspiegel darunter kaum zu finden sind.

Reinzers Meteorologia philosopbico-politica steht den didaktischen Emblembüchern der Dimlerschen Typologie nahe und teilt auch deren politische Zielrichtung. Doch bedenkt man, wie sehr das Werk auf den Kaiser und seinen Sohn, dem es gewidmet war, zugeschnitten ist, so muß der hohe Anteil an sachkundlich-naturwissenschaftlichem Lehrgut überraschen, das ja bei weitem den größten Teil des Bandes ausmacht. Auch innerhalb der Emblembuchtradition sucht die Meteorologia philosophicopolitica in dieser Hinsicht ihresgleichen; am ehesten wäre hier noch Michael Maiers Atalanta fugiens (Oppenheim 1618) zu nennen, ein alchemisch-allegorisches Werk, wo in ganz ähnlicher Weise der gelehrtalchemische Diskurs zum eigentlichen Emblem hinzutritt. ${ }^{152}$ Wer die Leser einer derart emblematisch gezierten Meteorologie gewesen sein mögen, darüber lassen sich nur Vermutungen anstellen. Immerhin scheint das Werk - wenn dies aus der Existenz einer deutschen Ubersetzung zu schließen ist - eine gewisse Popularität besessen zu haben. Zumindest war es nicht häufig, daß einem Text der neuaristotelischen Naturphilosophie dergleichen wiederfuhr. Die Provenienzen der mir bekannten Exemplare deuten darauf hin, daß der Adressatenkreis im adligen Milieu und dann aber vor allem an den Bildungsinstitutionen der Gesellschaft Jesu selbst zu suchen ist, wo Reinzers Meteorologie vielleicht nicht nur als didaktisches und naturkundliches Werk gelesen, sondern auch als ein tröstliches Meditationsbuch beschaut wurde: In einem Exemplar der Staats- und Stadtbibliothek Augsburg hat der Erstbesitzer, ein Abt aus Osterhofen in Niederbayern, auf dem Titelblatt vermerkt: "Comparavit Ferdinandus Abbas Osterhoviensis 1703 in medio tumultu bellorum »..$^{153}$

Das Ende der literarischen Wirkung der Meteorologia philosopbicopolitica fällt zusammen sowohl mit dem Niedergang der Emblematik überhaupt, als auch mit dem Tod Leopolds I. (1705) und Josephs I. (1711), mit deren beider Person das Werk inhaltlich so eng verbunden war. In der Geschichte der naturwissenschaftlichen Emblembücher markiert die Meteorologia philosopbico-politica Höhe- und Endpunkt

151 Vgl. auch G. R. Dimler, A Bibliographical Survey of Jesuit Emblem Authors in French Provinces, 1618-1726: Topography and Themes, "Archivum historicum Societatis Jesu ", 47, 1978, S. 240-250, hier S. 245.

152 Vgl. hierzu besonders H. M. E. DE Jong, Michael Maier's Atalanta Fugiens: Sources of an Alchemical Book of Emblems ("Janus Suppléments », 8), Leiden 1969.

153 Staats- und Stadtbibliothek Augsburg, Signatur $2^{\circ}$ Phil 79. 
zugleich; innerhalb des meteorologischen Schrifttums steht sie am Schnittpunkt $z$ wischen aristotelischem Traditionalismus und dem Eklektizismus der Frühaufklärung, zwischen den volkstümlichen, selbst die abstrusesten Berichte noch einschließenden Kompendien und dem Reduktivismus der modernen Naturwissenschaft. Vergleichen wir Reinzers Werk mit dem nur wenig zuvor entstandenen, voluminösen Der Wunder = reiche Uberzug unserer Nider $=$ Welt $/$ oder Erd =umgebende Luff $t=$ Kreys (Nürnberg 1680) des gelehrten Vielschreibers und Popularisators Erasinus Francisci, der in der Tradition von Daniel Schwenters weitverbreiteten Deliciae physico-mathematicae (Nürnberg 1636) auf mehr als 1450 Seiten nahezu alles zusammenträgt, was seit der Antike bis hin zu den Flugblättern und Zeitungen der jüngsten Zeit an Wetter- und Himmelserscheinungen berichtet worden ist, so fällt auf, daß bei Reinzer von all den fabulösen Begebenheiten, bizarren Unglücksfällen, zauberischen Luftfahrten, Wundererscheinungen, Frosch- und Hamsterregen einschließlich ihrer abergläubischen Vorbedeutungen kaum noch etwas übriggeblieben ist, obgleich beide Autoren aus nahezu den gleichen literarischen Quellen schöpfen. Hatte noch Francisci sein Werk im Titel «zu Ausbreitung Göttlicher Allmacht/ und Erlustigung deß curiösen Lesers » bestimmt, so ist Reinzers Meteorologia philosophico-politica von schulmäßiger Strenge und praktischer Vernunft geprägt. Natur ist zwar noch Bedeutungsträger, doch hat sich die metaphorische Ebene in der Sache bereits von der wissenschaftlichen Behandlung der Natur gelöst und wird nur mehr als Analogon auf diese bezogen.

Vergleichen wir Reinzers Meteorologie hingegen mit der im gleichen akademischen Milieu entstandenen und auf den ersten Blick ganz ähnlichen Natura et proprietates aeris ${ }^{154}$ des Ingolstädter Jesuitenprofessors Christoph Höchtl aus dem Jahre 1730, so wird deutlich, wohin die Entwicklung gehen sollte. Zwar ist aurh Höchtls 'Meteorologie' als Disputationsschrift eines gewissen Johann Franz Joseph von Rummel erschienen und Karl VI., dem zweiten Sohn Kaiser Leopolds und Nachfolger Josephs I. auf dem Kaiserthron gewidmet; zwar hängen auch ihr Thesen aus dem Gesamtgebiet der Philosophie und Wissenschaften an, die fast noch weiter ausgreifen als diejenigen, die Graf Roedern eine Generation zuvor in Linz zu verteidigen hatte; doch inhaltlich beschränkt sich der 170 Folioseiten starke Band fast ausschließlich auf die physikalischen Eigenschaften der Luft und deren experimentelle Bestimmung.

$154 \mathrm{CH}$. HöchtL, Natura et proprietaies aeris... una cum positionibus ex universa philosophia ... propugnata a ... JonNNE Francisco JosepHo ... Barone de Rummel a Waldau et Herrenrieth, Ingolstadt 1730. 
Ausgehend von der Unterscheidung zwischen Luft und den alten anathymiaseis ${ }^{155}$ werden dann raritas, gravitas und levitas und die elastischen Eigenschaften der Luft behandelt. Aerostatik und Thermometrie, das Vakuum und seine Erzeugung werden vorgestellt, Sturm und Descartes, Galilei und Boyle zitiert. Falttafeln präsentieren die Magdeburger Halbkugeln, Luftpumpen sowie aerostatische und pneumatische Versuchsanordnungen. Das «emblematische Zeitalter», wie Herder das 17. Jahrhundert genannt hat, ist zu Ende. Die experimentierende und quantifizierende Naturwissenschaft hatte auch hier als Zerstörerin der $\mathrm{Me}$ tapher den Sieg davongetragen.

\section{SCHLuss}

Es steht hier nicht zur Debatte, ob dies Verlust sei oder Gewinn. John Donnes Frage "whether the world did lose or gaine in this " aus der Anatomy of the World von 1611 dürfte eine der frühesten Reaktionen auf die Zerstörung der alten Sinnbezüge durch die neue Wissenschaft gewesen sein: ${ }^{156}$

And new Philosophy calls all in doubt,

The Element of fire is quite put out;

The Sun is lost, and th'earth, and no mans wit

Can well direct him where to looke for it.

And freely men confesse that this world's spent,

When in the Planets, and the Firmament

They seeke so many new; they see that this

Is crumbled out againe to his Atomies.

'Tis all in peeces, all cohaerence gone;

All just supply, and all Relation. ${ }^{17}$

[...]

The art is lost, and correspondence too.

For heaven gives little, and the earth takes lesse,

And man least knowes their trade and purposes. ${ }^{158}$

155 Zur Bedeutung dieser Unterscheidung siehe Middleton (wie Anm. 66), S. 20-42.

$156 \mathrm{Vgl}$. dazu auch J. KLEIN, Astronomie und Anthropozentrik: Die Copernicanische Wende bei John Donne, John Milton und den Cambridge Platonists ( Aspekte der englischen Geistes- und Kulturgeschichte », 6), Frankfurt-Bern-New York 1986, bes. S. $194-216$.

157 J. Donne, An Anatomy of the World: The first Anniversary [1611], Z. 205-214, in The Poems of John Donne, hrsg. von H. J. C. Grierson, Bd. I, Oxford 1912, S. 237.

158 Ebenda, Z. 396-399, S. 243. 
Bei Reinzer, mehr als acht Jahrzehnte danach, besitzt Natur zwar noch ihre alte Bedeutungsdimension, doch nur mehr in der analogen Parallelisierung von Naturgesetz und Moralgesetz; denn der Wirkungszusammenhang der Teile mit seinem Ganzen ist endgültig dahin. Ein halbes Jahrhundert darauf kann Winckelmann bereits spöttisch auf jene Zeit herabsehen,

wo ein großer Haufe der Gelehrten gleichsam zur Ausrottung des guten Geschmacks sich mit einer wahrhaften Raserey empörete. Sie fanden in dem, was Natur heißt, nichts als kindische Einfalt, und man hielt sich verbunden, dieselbe witziger zu machen. Junge und Alte fingen an, Devisen und Sinnbilder zu malen, nicht allein für Künstler, sondern auch für Weltweise und Gottesgelehrte. ${ }^{159}$

Es versteht sich, daß der Wissenschaftshistoriker sich von einem Werk wie von Reinzers emblematischer Meteorologia philosopbico-politica kaum Aufschlüsse über den Fortgang der Erkenntnis und die Weiterentwicklung der naturwissenschaftlichen Methode erwarten darf. Im besten Falle spiegelt es den damaligen Stand des Wissens getreu wider und läßt den Fragehorizont frühneuzeitlicher Naturwissenschaft deutlich werden. Zugleich aber weist es auf den konkreten historischen Ort seines Entstehens, Autoren und Leser, schulisches Milieu und gesellschaftliches Umfeld. Wir werden gewahr, wie Naturwissenschaft, und in diesem Fall sogar eine recht spezielle Naturwissenschaft, bestehen und sich entfalten konnte außerhalb derjenigen Institutionen und sozialen Vorbedingungen, die wir für gewöhnlich mit dem Zeitalter der Naturwissenschaftlichen Revolution in Verbindung bringen.

Aber auch für die Historiographie der Naturwissenschaften wird an einem Werk wie diesem etwas deutlich, was, wie ich meine, bisher viel zu wenig Beachtung erfahren hat. Die Ar $\_$und Weise, wie die Meteorologia philosopbico-politica Gegenstände aus der bistoria naturalis und der bistoria artificialis bildlich in Szene setzt und ihnen implizit eine Botschaft zuweist, die über die res picta hinausreicht, wie dies zum Wesen des Sinnbildes gehört, scheint dem, was wir unter einer naturwissenschaftlichen Abbildung verstehen, diametral entgegengesetzt. Und doch ist der Unterschied $\mathrm{zu}$ den rein naturwissenschaftlich-technischen und vermeintlich ganz expliziten Illustrationen geringer, als man annehmen möchte. Wir brauchen nicht einmal die barocke Bilderpracht von Guerickes Experimenta nova zu nehmen; schon Georg Agricolas De re metal-

159 J. J. WinckelmanN, Gedanken von der Nachabmung der griechischen Werke [1756], zit. nach: Emblemata (wie Anm. 121), S. IX. 
lica und noch die Tafeln der Encyclopédie von Diderot und D'Alembert entfalten eine bildliche Rhetorik, die der Demonstration und Legitimation eines bestimmten Wissenschaftsideals galt und zu diesem Ziele auch Elemente des Normensystems der Wissenschaft, wie Offentlichkeitscharakter, Kollektivität, Präzision, Detailtreue und mathematisch-geometrische Strenge, im Bild inszenierte. Die Bildrhetorik der courtly treatises und courtly fantasies des ausgehenden Mittelalters ${ }^{160}$ und die argumentative Verwendung des emblematischen Bildes im Schrifttum der Jesuiten des 17. Jahrhunderts setzt sich mit anderen Mitteln bis in die naturwissenschaftliche und technische Illustration der Gegenwart fort. All dies ist bisher noch kaum thematisiert, geschweige denn methodisch berücksichtigt worden. Hier wären neue gattungs- und motivgeschichtliche, aber auch kunst- und literatursoziologische Untersuchungen zur naturwissenschaftlichen Ikonographie und Ikonologie vonnöten.

\section{SUMMARY}

The history of early modern meteorology has been almost entirely neglected by historians of science. In fact the ancient science of bodies between earth and heaven, bound to the framework of Aristotelian cosmology for centuries, has little in common with the physics of the atmosphere which divorced itself from its homonymous predecessor during the nineteenth century. Reinzer's Meteorologia, a most unusual synthesis of emblem book, princely advice, and textbook of meteorology, reveals the historical place of a branch of natural science that remained off the main course of the Scientific Revolution, a branch of science however, that flourished within the peculiar social, educational and intellectual context provided by an Austrian Jesuit college during the last decade of the seventeenth century.

160 B. S. Hals, Editing Texts in the History of Early Technology, in Editing Texts in the History of Science and Medicine, hrsg. von T. H. Levere, New York-London 1982, S. 69-100, hier bes. S. 77-78. 